\title{
Multi axis differential optical absorption spectroscopy (MAX-DOAS)
}

\author{
G. Hönninger ${ }^{1,{ }^{*}}$, C. von Friedeburg ${ }^{1}$, and U. Platt ${ }^{1}$ \\ ${ }^{1}$ Institut für Umweltphysik, Universität Heidelberg, Heidelberg, Germany \\ *now at: Meteorological Service of Canada, Toronto, Canada
}

Received: 10 October 2003 - Published in Atmos. Chem. Phys. Discuss.: 11 November 2003

Revised: 31 January 2004 - Accepted: 31 January 2004 - Published: 9 February 2004

\begin{abstract}
Multi Axis Differential Optical Absorption Spectroscopy (MAX-DOAS) in the atmosphere is a novel measurement technique that represents a significant advance on the well-established zenith scattered sunlight DOAS instruments which are mainly sensitive to stratospheric absorbers. MAX-DOAS utilizes scattered sunlight received from multiple viewing directions. The spatial distribution of various trace gases close to the instrument can be derived by combining several viewing directions. Ground based MAX-DOAS is highly sensitive to absorbers in the lowest few kilometres of the atmosphere and vertical profile information can be retrieved by combining the measurements with Radiative Transfer Model (RTM) calculations. The potential of the technique for a wide variety of studies of tropospheric trace species and its (few) limitations are discussed. A Monte Carlo RTM is applied to calculate Airmass Factors (AMF) for the various viewing geometries of MAX-DOAS. Airmass Factors can be used to quantify the light path length within the absorber layers. The airmass factor dependencies on the viewing direction and the influence of several parameters (trace gas profile, ground albedo, aerosol profile and type, solar zenith and azimuth angles) are investigated. In addition we give a brief description of the instrumental MAX-DOAS systems realised and deployed so far. The results of the RTM studies are compared to several examples of recent MAXDOAS field experiments and an outlook for future possible applications is given.
\end{abstract}

\section{Introduction}

The analysis of the atmospheric composition by scattered sunlight absorption spectroscopy in the visible/near ultraviolet spectral ranges has a long tradition. This application is also called "passive" absorption spectroscopy in contrast to

Correspondence to: G. Hönninger

(Gerd.Hoenninger@ec.gc.ca) spectroscopy using artificial light sources (i.e. active DOAS, Perner et al., 1976; Platt et al., 1979; Perner and Platt, 1979; Platt and Perner, 1980; Platt et al., 1980).

Shortly after Dobson and Harrison (1926) conducted measurements of atmospheric ozone by passive absorption spectroscopy, the "Umkehr" technique (Götz et al., 1934), which was based on the observation of a few (typically 4) wavelengths, allowed the retrieval of ozone concentrations in several atmospheric layers yielding the first vertical profiles of ozone.

The COSPEC (COrrelation SPECtrometer) technique developed in the late 1960s was the first attempt to study tropospheric species by analysing scattered sunlight in a wider spectral range while making use of the detailed structure of the absorption bands with the help of an opto-mechanical correlator (Millan et al., 1969; Davies, 1970). It has now been applied for over more than three decades for measurements of total emissions of $\mathrm{SO}_{2}$ and $\mathrm{NO}_{2}$ from various sources, e.g. industrial emissions (Hoff and Millan, 1981) and - in particular - volcanic plumes (e.g. Stoiber and Jepsen, 1973; Hoff et al., 1992).

Scattered sunlight was later used in numerous studies of stratospheric and (in some cases) tropospheric $\mathrm{NO}_{2}$ as well as other stratospheric species by ground-based differential optical absorption spectroscopy (DOAS), as summarised in Table 1. This was a significant step forward, since the quasicontinuous wavelength sampling of DOAS instruments in typically hundreds of spectral channels allows the detection of much weaker absorption features and thus higher sensitivity. This is due to the fact that the differential absorption pattern of the trace gas cross section is unique for each absorber and its amplitude can be readily determined by a fitting procedure using for example least squares methods to separate the contributions of the individual absorbers. The simultaneous measurement of several absorbers is possible while cross-interferences and the influence of Mie scattering are virtually eliminated. 
Table 1. Overview and history of the different scattered light passive DOAS applications, \# Axis indicates the number of different viewing directions combined.

\begin{tabular}{|c|c|c|c|}
\hline Method & $\begin{array}{l}\text { Measured } \\
\text { quantity }\end{array}$ & $\begin{array}{l}\text { No. of axes, } \\
\text { technique }\end{array}$ & References \\
\hline COSPEC & $\mathrm{NO}_{2}, \mathrm{SO}_{2}, \mathrm{I}_{2}$ & $1,(\mathrm{~S})$ & $\begin{array}{l}\text { Millan et al. (1969), Davies (1970), Hoff } \\
\text { and Millan (1981), Stoiber and Jepsen } \\
\text { (1973), Hoff et al. (1992) }\end{array}$ \\
\hline $\begin{array}{l}\text { Zenith scattered } \\
\text { light DOAS }\end{array}$ & $\begin{array}{l}\text { Stratospheric } \mathrm{NO}_{2}, \mathrm{O}_{3} \\
\text { OClO, BrO, IO }\end{array}$ & 1 & $\begin{array}{l}\text { Noxon (1975), Noxon et al. (1979), Harri- } \\
\text { son (1979), McKenzie and Johnston (1982), } \\
\text { Solomon et al. (1987a, b, 1988, 1989, } \\
\text { 1993), McKenzie et al. (1991), Fiedler et } \\
\text { al. (1993); Pommereau and Piquard (1994), } \\
\text { Aliwell et al. (1997); Eisinger et al. (1997); } \\
\text { Kreher et al. (1997); Richter et al. (1999); } \\
\text { Wittrock et al. (2000) }\end{array}$ \\
\hline $\begin{array}{l}\text { Zenith sky }+ \text { Off- } \\
\text { Axis DOAS }\end{array}$ & Stratospheric $\mathrm{OClO}$ & 2 & Sanders et al. (1993) \\
\hline Off-Axis DOAS & $\begin{array}{l}\text { Stratospheric BrO pro- } \\
\text { file }\end{array}$ & 1 & Arpaq et al. (1994) \\
\hline $\begin{array}{l}\text { Zenith scattered } \\
\text { light DOAS }\end{array}$ & Tropospheric IO, BrO & 1 & $\begin{array}{l}\text { Kreher et al. (1997); Friess et al. (2001, } \\
\text { 2004), Wittrock et al. (2000) }\end{array}$ \\
\hline Off axis DOAS & Tropospheric $\mathrm{BrO}$ & 1 & Miller et al. (1997) \\
\hline $\begin{array}{lr}\text { Sunrise } & \text { Off-Axis } \\
\text { DOAS+ } & \text { direct } \\
\text { moonlight } & \end{array}$ & $\mathrm{NO}_{3}$ profiles & $2, S$ & $\begin{array}{l}\text { Weaver et al. (1996), Smith and } \\
\text { Solomon (1990), Smith et al. (1993) }\end{array}$ \\
\hline
\end{tabular}

Scattered sunlight DOAS measurements yield "slant" column densities of the respective absorbers. Most observations were done with zenith looking instruments because the radiative transfer modelling necessary for the determination of vertical column densities is best understood for zenith scattered sunlight. On the other hand, for studies of trace species near the ground, artificial light sources (usually high pressure Xenon short arc lamps) were used in active Long-path DOAS experiments (e.g. Perner et al., 1976; Perner and Platt, 1979; Platt et al., 1979; Mount, 1992; Plane and Smith, 1995; Axelson et al., 1990; Harder et al., 1997; Stutz and Platt, 1997). These active DOAS measurements yield trace gas concentrations averaged along the several kilometre long light path, extending from a searchlight type light source to the spectrometer. Active DOAS instruments have the advantage of allowing measurements to be made independent of daylight and at wavelengths below $300 \mathrm{~nm}$, however, they require a much more sophisticated optical system, more maintenance, and one to two orders of magnitude more power than passive instruments (e.g. Platt, 1994). Therefore a type of instrument allowing measurements of trace gases near the ground like active DOAS, while retaining the simplicity and selfsufficiency of a passive DOAS instrument, is highly desirable.
Passive DOAS observations, essentially all using light scattered in the zenith, had already been performed for many years (see Table 1) when the "Off-Axis" geometry (i.e. observation at directions other than towards the zenith) for measurements of scattered sunlight was first introduced by Sanders et al. (1993) to observe OClO over Antarctica during twilight. The strategy of their study was to observe $\mathrm{OClO}$ in the stratosphere using scattered sunlight as long into the "polar night" as possible. As the sun rises or sets, the sky is of course substantially brighter towards the horizon in the direction of the sun compared to the zenith. Thus the light intensity and therefore the signal to noise ratio is improved significantly. Sanders et al. (1993) also pointed out that the off-axis geometry increases the sensitivity for lower absorption layers. They concluded that absorption by tropospheric species (e.g. $\left.\mathrm{O}_{4}\right)$ is greatly enhanced in the off-axis viewing mode, whereas for an absorber in the stratosphere (e.g. $\mathrm{NO}_{2}$ ) the absorptions for zenith and off-axis geometries are comparable. Arpaq et al. (1994) used their off-axis observations during morning and evening twilight to derive information on stratospheric $\mathrm{BrO}$ at mid-latitudes, including some altitude information from the change in the observed columns during twilight. At the time of the measurements of Arpaq et al. (1994) the available radiative transfer models 
Table 1. Continued.

\begin{tabular}{|c|c|c|c|}
\hline Method & $\begin{array}{l}\text { Measured } \\
\text { quantity }\end{array}$ & $\begin{array}{l}\text { No. of axes, } \\
\text { technique }\end{array}$ & References \\
\hline $\begin{array}{l}\text { Sunrise Off Axis } \\
\text { DOAS }\end{array}$ & $\begin{array}{l}\text { Tropospheric } \mathrm{NO}_{3} \text { pro- } \\
\text { files }\end{array}$ & 1 & Kaiser (1997), von Friedeburg et al. (2002) \\
\hline Aircraft-DOAS & Stratospheric $\mathrm{NO}_{2}$ & 1 & Wahner et al. (1989) \\
\hline Aircraft-DOAS & Tropospheric BrO & 2 & McElroy et al. (1999) \\
\hline $\begin{array}{l}\text { Aircraft zenith sky } \\
+ \text { Off-axis DOAS }\end{array}$ & $\begin{array}{l}\text { "near in-situ" strato- } \\
\text { spheric } \mathrm{O}_{3}\end{array}$ & 3 & Petritoli et al. (2002) \\
\hline AMAX-DOAS & Trace gas profiles & $8+, \mathrm{M}$ & $\begin{array}{l}\text { Wagner et al. (2002), Wang et al. (2003), } \\
\text { Heue et al. (2003) }\end{array}$ \\
\hline Multi-Axis-DOAS & $\begin{array}{l}\text { Tropospheric BrO pro- } \\
\text { files }\end{array}$ & $4, S$ & $\begin{array}{l}\text { Hönninger and Platt (2002), Hönninger et } \\
\text { al. (2004a) }\end{array}$ \\
\hline Multi-Axis-DOAS & Trace gas profiles & $2-4, \mathrm{M}$ & $\begin{array}{l}\text { Löwe et al. (2002), Oetjen (2002), Heckel } \\
\text { (2003), Wittrock et al. (2003) }\end{array}$ \\
\hline Multi-Axis-DOAS & $\mathrm{NO}_{2}$ plume & $8, \mathrm{M}$ & von Friedeburg (2003) \\
\hline Multi-Axis-DOAS & $\begin{array}{l}\mathrm{BrO} \text { in the marine } \\
\text { boundary layer }\end{array}$ & $6, \mathrm{~S} / \mathrm{M}$ & Leser et al. (2003), Bossmeyer (2002) \\
\hline Multi-Axis-DOAS & $\begin{array}{l}\mathrm{BrO} \text { and } \mathrm{SO}_{2} \text { fluxes } \\
\text { from volcanoes }\end{array}$ & $10, \mathrm{~S}$ & Bobrowski et al. (2003) \\
\hline Multi-Axis-DOAS & $\begin{array}{l}\text { BrO emissions from } \\
\text { Salt Lake }\end{array}$ & $4, S$ & Hönninger et al. (2004b) \\
\hline
\end{tabular}

$\mathrm{S}=$ Scan, $\mathrm{M}=$ Multiple telescopes

were single scattering approximations for the off-axis viewing mode, which was sufficient for the study of stratospheric absorbers.

In spring 1995 Miller et al. (1997) conducted off-axis measurements at Kangerlussuaq, Greenland in order to study tropospheric $\mathrm{BrO}$ and $\mathrm{OClO}$ related to boundary layer ozone depletion after polar sunrise. These authors observed at off-axis angles (i.e. angle between zenith and observation direction) of $87^{\circ}$ and $85^{\circ}$, respectively, to obtain a larger signal due to the absorption by the tropospheric BrO fraction. No comparison was reported between off-axis and zenith sky measurements. The twilight behaviour of the slant columns was used to identify episodes of tropospheric BrO.

Off-axis DOAS, partly in combination with using the moon as direct light source, was also employed for the measurement of stratospheric and tropospheric profiles of $\mathrm{NO}_{3}$ by ground based instruments (Weaver et al., 1996; Smith and Solomon, 1990; Smith et al., 1993; Kaiser, 1997; von Friedeburg et al., 2002).

An overview of the different DOAS measurement configurations and the respective measured quantities reported to date is given in Table 1 .

Here we present a new approach to the problem of measuring tropospheric species by observing their absorption in scattered sunlight. This technique combines the advantages of all preceding attempts and introduces several new concepts: Combination of measurements at several viewing angles, multiple scattering radiative transport modelling, and the use of the $\mathrm{O}_{4}$ absorption to quantify Mie scattering and aerosols. It allows the study of atmospheric trace gases close to the instrument (i.e. in the boundary layer with ground based instruments) with extreme sensitivity and some degree of spatial resolution. While the approaches developed in inversion theory (e.g. Rodgers, 1976) can - and will in the future - be applied to MAX-DOAS, no mathematical inversion was attempted in this study. Profile information was rather derived from the comparison of measurements and various forward modelled profiles. MAX-DOAS instruments are very simple in their set-up and can be used from the ground as well as from various airborne platforms.

\section{The DOAS technique}

Differential Optical Absorption Spectroscopy (DOAS) is a technique that identifies and quantifies trace gas abundances with narrow band absorption structures in the near UV and visible wavelength region in the open atmosphere (e.g. Platt, 
1994). The fundamental set-up of a DOAS system consists of a broadband light source, an optical set-up that transfers the light through the atmosphere, and a telescope - spectrograph - detector system to record the absorption spectra. The basic idea of DOAS is to separate the trace gas absorption cross section into two parts, one that varies "slowly" with wavelength, and a rapidly varying differential cross section $\sigma^{\prime}$. The latter can be thought of as absorption lines or bands. Broadband extinction by Mie scattering, instrumental effects and turbulence are difficult to quantify, therefore these interferences have to be corrected to derive trace gas concentrations. If the same filtering procedure is applied to the atmospheric absorption spectrum, the narrow band absorption can be used to calculate the trace gas concentrations (Platt, 1994). The advantages of DOAS are the ability to detect extremely weak absorptions (O.D. $\sim 10^{-4}$ ), the unequivocal and absolute identification of the trace gases, as well as the fact that trace gas concentrations are determined solely from the absorption cross section. A calibration is therefore not necessary. DOAS uses the Beer-Lambert law with modified source intensity $I_{0}^{\prime}$ and absorption cross section $\sigma^{\prime}$ to eliminate contributions that vary only "slowly" with wavelength:

$I(\lambda)=I_{0}^{\prime}(\lambda) \cdot e^{-\sigma^{\prime}(\lambda) \cdot S}$

$S$ : Slant Column Density (SCD).

There are several aspects which are characteristic of scattered sunlight measured by passive DOAS instruments:

\subsection{The Fraunhofer reference spectrum}

The solar radiation can be described, in first approximation, as the continuous emission of a black body with $T \approx 5800 \mathrm{~K}$. This continuum, however, is overlaid by a large number of strong absorption lines called the Fraunhofer lines. These lines are due to selective absorption and re-emission of radiation by atoms in the solar photosphere. Many solar Fraunhofer lines are dominant in scattered sunlight DOAS, especially in the UV and visible spectral range (300-600 nm) and are substantially stronger than absorption due to most constituents of the terrestrial atmosphere.

Fraunhofer lines have to be carefully removed in the DOAS analysis procedure in order to evaluate the absorption structures of the much weaker absorptions due to trace gases in the earth's atmosphere (optical densities of $10^{-3}$ and less compared to Fraunhofer lines with up to $30 \%$ absorption at typical DOAS spectral resolution). A so-called Fraunhofer reference spectrum (FRS) is always included in the fitting process for the MAX-DOAS evaluation of scattered sunlight spectra (for details on the DOAS fit see Stutz and Platt, 1996). This spectrum can either be a single, carefullychosen background spectrum or a new FRS for each series of MAX-DOAS at different viewing directions. In the former case usually one fixed FRS, taken at small solar zenith angle and zenith observation geometry for minimum trace gas absorption, is used to evaluate differential slant column densities (DSCD, $S_{D}$ ), which are differential with respect to this FRS. So called "tropospheric difference" slant column densities $\triangle \mathrm{SCD}(\triangle \mathrm{S})$ are calculated from these DSCD's by subtracting the DSCD of the zenith viewing direction containing minimum tropospheric absorptions from the respective DSCD's of the other viewing directions:

$$
\begin{aligned}
& \frac{I(\lambda)}{I_{\mathrm{FRS}}(\lambda)}=e^{-\sigma^{\prime}(\lambda) \cdot\left(S-S_{\mathrm{FRS}}\right)} \rightarrow S_{D}=S-S_{\mathrm{FRS}}=\frac{\ln \frac{I_{\mathrm{FRS}}(\lambda)}{I(\lambda)}}{\sigma^{\prime}(\lambda)} \forall \lambda \\
& \Delta \mathrm{S}=S_{D, \alpha \neq 90^{\circ}-S_{D, \alpha=90^{\circ}}}
\end{aligned}
$$

The latter approach directly yields $\triangle$ SCD's for the used viewing directions, which can be compared to model results (see below).

$\Delta S=S_{\alpha \neq 90^{\circ}}-S_{\alpha=90^{\circ}}$.

Here, $\alpha$ denotes the elevation angle (angle between the viewing direction and the horizontal direction), which is commonly used to characterise MAX-DOAS viewing directions. Since in most cases the zenith direction $\left(\alpha=90^{\circ}\right)$ has been used as background FRS, DSCD's and $\triangle$ SCD's are defined relative to the zenith direction. It should be noted that both ways of calculating $\triangle$ SCD's yield, of course, the same results.

$$
\begin{aligned}
& \Delta S=S_{D, \alpha \neq 90^{\circ}}-S_{D, \alpha=90^{\circ}} \\
& =\left(S_{\alpha \neq 90^{\circ}}-S_{\mathrm{FRS}}\right)-\left(S_{\alpha=90^{\circ}}-S_{\mathrm{FRS}}\right) \\
& =S_{\alpha \neq 90^{\circ}}-S_{\alpha=90^{\circ}}=\Delta S .
\end{aligned}
$$

\subsection{The Ring effect}

The Ring effect - named after Grainger and Ring (1962) leads to a reduction of the observed optical densities of solar Fraunhofer lines depending on the atmospheric light path. For example, Fraunhofer lines observed at large solar zenith angles (SZA) appear weaker ("filled in") than the same lines at small SZA. Precise measurements can only be made if this effect is compensated for, otherwise complete removal of Fraunhofer lines by division of spectra taken at small and large SZA, respectively, is impossible. Rotational Raman scattering is thought to be the most probable cause for the Ring effect (Kattawar et al., 1981; Bussemer, 1993; Fish and Jones, 1995; Burrows et al., 1996; Sioris et al., 1999). Optical density changes due to the Ring effect are of the order of a few percent, which significantly affects DOAS measurements of scattered radiation. Thus a very accurate correction is required, since the atmospheric absorptions which are evaluated are sometimes more than an order of magnitude smaller than the filling in of the Fraunhofer lines. Therefore a so called Ring reference spectrum is included in the DOAS fitting process when scattered sunlight spectra are evaluated. Fit coefficients derived for the Ring effect in MAX-DOAS measurements can for example be used to detect light path enhancements due to multiple scattering and possibly investigate other aspects of the radiative transfer. 

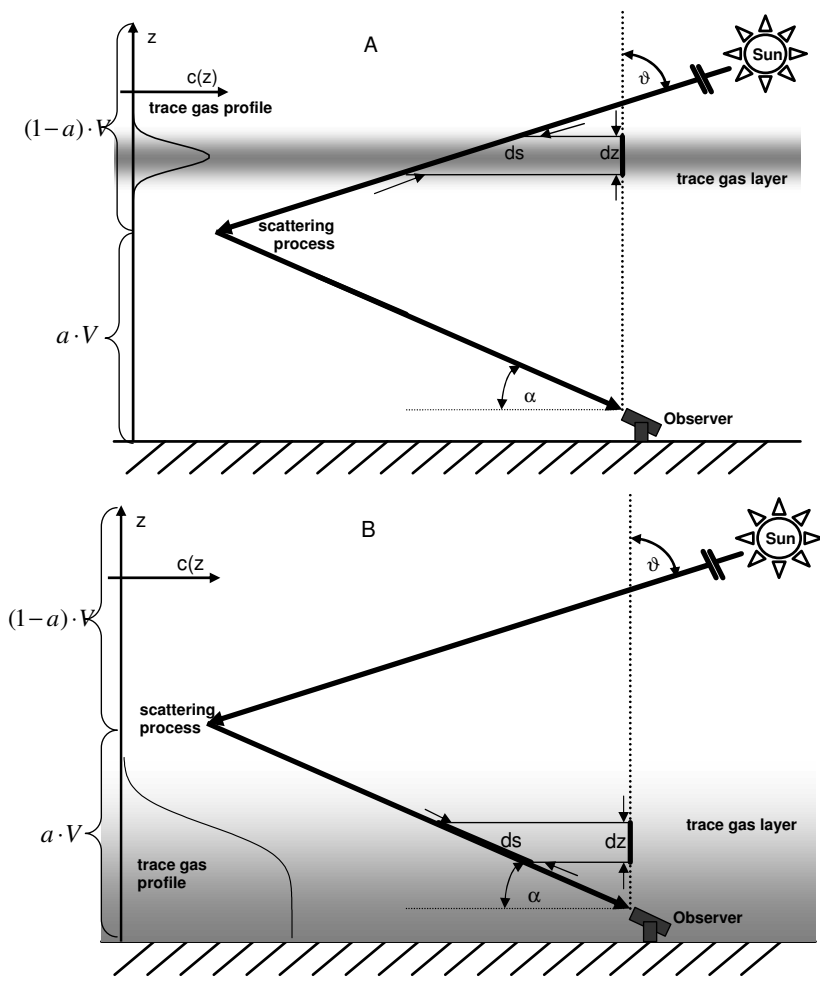

Fig. 1. Observation geometries for ground based DOAS using scattered sunlight: Light enters the atmosphere at a certain solar zenith angle $\vartheta$. In the single scattering approximation light received by the observer was scattered exactly once into the telescope viewing direction defined by the observation elevation angle $\alpha$. The observed SCD (integral along $d s$ ) is larger than the VCD (integral along $d z$ ), with AMF being the conversion factor. Panel A represents the situation for a high (stratospheric) trace gas layer, panel B is representative for a trace gas layer near the surface.

For a more comprehensive discussion of effects that have to be addressed when using scattered sunlight for DOAS measurements see also (Solomon, 1987b; Platt et al., 1997).

\subsection{The $\mathrm{O}_{4}$ spectrum}

The oxygen dimer $\mathrm{O}_{4}$ is another important parameter for MAX-DOAS. $\mathrm{O}_{4}$ is also referred to as $\left(\mathrm{O}_{2}\right)_{2}$ to point out that it is a collisional complex rather than a bound molecule. Absorption bands of $\mathrm{O}_{4}$ occur at several wavelengths in the UV/Vis spectral range (Perner and Platt 1980). Therefore an $\mathrm{O}_{4}$ reference spectrum (Greenblatt et al., 1990) is often included in the DOAS analysis. $\mathrm{O}_{4}$ has been used in many cases to characterize the effects of multiple scattering in clouds and other aspects of the radiative transfer on DOAS measurements of scattered sunlight (Erle et al., 1995; Wagner et al., 1998; Pfeilsticker et al., 1998; Wagner et al., 2002). For MAX-DOAS measurements $\mathrm{O}_{4}$ can be used to determine the importance of multiple scattering and to derive aerosol profile information (see Sect. 4, sensitivity studies, below).

\section{MAX-DOAS (geometric approach)}

The calculation of path average trace gas concentrations from slant column density measurements using direct sunlight or active DOAS arrangements is straightforward. In the case of the analysis and interpretation of DOAS measurements using scattered sunlight, where the radiation can travel along multiple paths, it is crucial to correctly describe the radiative transfer in the atmosphere (Marquard et al., 2000). The apparent absorption of trace gases with distinct vertical profiles (e.g. $\mathrm{O}_{3}, \mathrm{NO}_{2}, \mathrm{BrO}$ ) measured by a ground based spectrometer depends strongly on the distribution of the paths taken by the registered photons on their way through the atmosphere. DOAS measurements using scattered sunlight yield apparent slant column densities (SCD) S, which are defined as the trace gas concentration integrated along the effective light path (in reality it is an average of an infinite number of different light paths).

$S=\int_{0}^{L} c(s) d s$

for direct light: $\bar{c}=\frac{S}{L}, \bar{c}:$ average concentration.

Note that for a single SCD measurement the individual photons registered in the detector have travelled different paths through the atmosphere before being scattered into the DOAS telescope. Therefore Eq. (5) can only account for the most probable path defined as an average over a large number of registered photons. Since the SCD depends on the observation geometry and the current meteorological conditions, it is usually converted to the vertical column density (VCD) $V$, which is defined as the trace gas concentration $c(z)$ integrated along the vertical path through the atmosphere:

$V=\int_{0}^{\infty} c(z) d z$.

The concept of air mass factors has been used for interpreting zenith-scattered light DOAS observations for many years (e.g. Solomon et al., 1987b; Perliski and Solomon, 1993). The air mass factor (AMF) $\mathrm{A}$ is defined as the ratio of SCD and VCD:

$A(\lambda, \vartheta, \alpha, \phi)=\frac{S(\lambda, \vartheta, \alpha, \phi)}{V}$,

where $\vartheta$ denotes the solar zenith angle (SZA), $\alpha$ the telescope elevation angle and $\phi$ the relative azimuth angle, which is defined as the azimuth angle between the telescope direction and the sun. Taking into account the distribution of different light paths leads to an improved airmass factor concept (Marquard et al., 2000).

The observation geometry and the respective angles are shown in Fig. 1. For simplicity the relative azimuth angle 
Table 2. Summary of vertical profile shapes used in this study.

\begin{tabular}{|c|c|c|}
\hline $\begin{array}{l}\text { Profile } \\
\text { number }\end{array}$ & Profile shape & Atmospheric counterpart \\
\hline $\mathrm{P} 1$ & $c=c_{0}$ for $0-1 \mathrm{~km}, c=0$ above & $\begin{array}{l}\text { Absorber confined to well mixed } \\
1 \mathrm{~km} \text { boundary layer BL }\end{array}$ \\
\hline $\mathrm{P} 2$ & $c=c_{0}$ for $0-2 \mathrm{~km}, c=0$ above & $\begin{array}{l}\text { Absorber confined to well mixed } \\
2 \mathrm{~km} \mathrm{BL}\end{array}$ \\
\hline P3 & $\begin{array}{l}c=2 c_{0} \text { for } 0-1 \mathrm{~km}, c=c_{0} \text { for } 1-2 \mathrm{~km}, \\
c=0 \text { above }\end{array}$ & $\begin{array}{l}\text { Absorber mixing from } \mathrm{BL} \text { to higher } \\
\text { altitudes }\end{array}$ \\
\hline $\mathrm{P} 4$ & $\begin{array}{l}c=0 \text { for } 0-1 \mathrm{~km}, c=c_{0} \text { for } 1-2 \mathrm{~km}, \\
c=0 \text { above }\end{array}$ & $\begin{array}{l}\text { Absorber present in layer lifted from } \\
\text { the ground }\end{array}$ \\
\hline P5 & $c \propto\left[c\left(\mathrm{O}_{2}\right)\right]^{2}$ & $\mathrm{O}_{4}$ profile \\
\hline P6 & $\begin{array}{l}\text { Gaussian shape around } 25 \mathrm{~km} \text { altitude, } \\
10 \mathrm{~km} \text { FWHM }\end{array}$ & Stratospheric absorber (e.g. $\mathrm{O}_{3}, \mathrm{NO}_{2}$ ) \\
\hline P7 & $\begin{array}{l}c=0 \text { for } 0-3 \mathrm{~km}, c=c_{0} \text { for } 3-5 \mathrm{~km}, \\
c=0 \text { above }\end{array}$ & Absorber in lower free troposphere \\
\hline P8 & $\begin{array}{l}c=0 \text { for } 0-3 \mathrm{~km}, c=c_{0} \text { for } 7-9 \mathrm{~km}, \\
c=0 \text { above }\end{array}$ & Absorber in higher free troposphere \\
\hline
\end{tabular}

Table 3. Summary of parameters used for the simulations in this study.

\begin{tabular}{ll}
\hline Parameter & Values \\
\hline wavelength & $352 \mathrm{~nm}$ \\
telescope elevation angle $\alpha$ & $2^{\circ}, 5^{\circ}, 10^{\circ}, 20^{\circ}, 30^{\circ}, 40^{\circ}, 60^{\circ}, 90^{\circ}$ \\
telescope aperture angle & $0.4^{\circ}$ \\
relative azimuth angle $\phi$ & $90^{\circ}\left(2^{\circ}-180^{\circ}\right.$ in Section 4.6) \\
solar zenith angle $\vartheta$ & $30^{\circ}\left(0^{\circ}-92^{\circ}\right.$ in Section 4.7) \\
vertical grid & $100 \mathrm{~m}$ between $0 \mathrm{~km}$ and $3 \mathrm{~km}$ \\
& $500 \mathrm{~m}$ between $3 \mathrm{~km}$ and $5 \mathrm{~km}$ \\
& $1 \mathrm{~km}$ between $5 \mathrm{~km}$ and $70 \mathrm{~km}$ \\
\hline
\end{tabular}

$\phi$ is assumed to be $180^{\circ}$ here. The AMF depends on the radiative transfer in the atmosphere and is therefore also influenced by the profiles of several parameters including trace gas concentration, pressure, temperature, profiles of strong absorbers (e.g. ozone) and aerosols (including clouds) as well as the surface albedo.

Taking a as the fraction of the total vertical trace gas column $V$ residing below the scattering altitude we obtain the SCD (in the single scattering approximation sketched in Fig. 1):

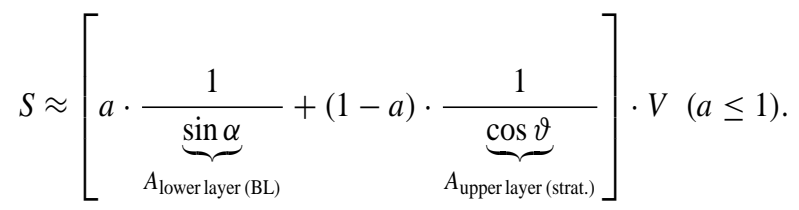

Therefore, an absorber near the ground (e.g. in the boundary layer) enhances the airmass factor according to approximately a $1 / \sin \alpha$ relation, expressing the strong dependence of the AMF on the elevation angle $\alpha$. In contrast, the airmass factor strongly depends on the solar zenith angle $\vartheta$ with approximately a $1 / \cos \vartheta$ relation for an absorber in the higher atmosphere (e.g. in the stratosphere).

\section{Radiative transfer calculation of MAX-DOAS air- mass factors}

A set of trace gas column measurements performed at a series of different elevation angles can be used to infer the vertical trace gas profile and thus the absolute concentration of the trace gas as a function of altitude. In addition, the aerosol optical density can be quantified from the variation with the observation geometry of the SCD of species with known concentration (such as $\mathrm{O}_{2}$ and $\mathrm{O}_{4}$ ). An actual profile inversion algorithm (e.g. Rodgers, 1976) was not yet implemented for MAX-DOAS at the current stage. Instead we apply the approach to perform a series of simulations for a number of possible profiles and subsequently choose the "best fit" as the most likely profile. In order to characterise the role of various parameters sensitivity studies are presented here.

As mentioned above, the geometric, single scattering approach using the equation $\mathrm{A} \sim 1 / \cos \vartheta$ (for scattering below the trace gas layer), where $\vartheta$ is the solar zenith angle, or A $\sim 1 / \sin \alpha$ (for scattering above the trace gas layer), where $\alpha$ is the telescope elevation angle, can only be regarded as an approximation. In particular factors influencing the result like Mie scattering, ground albedo, or arbitrary distributions of trace gases can only be quantified by radiative transfer calculations. In the following we present a study to illustrate some of the properties of the MAX-DOAS technique.

Precise air mass factors for this study were calculated using the Monte Carlo radiative transfer model (RTM) "Tracy" 

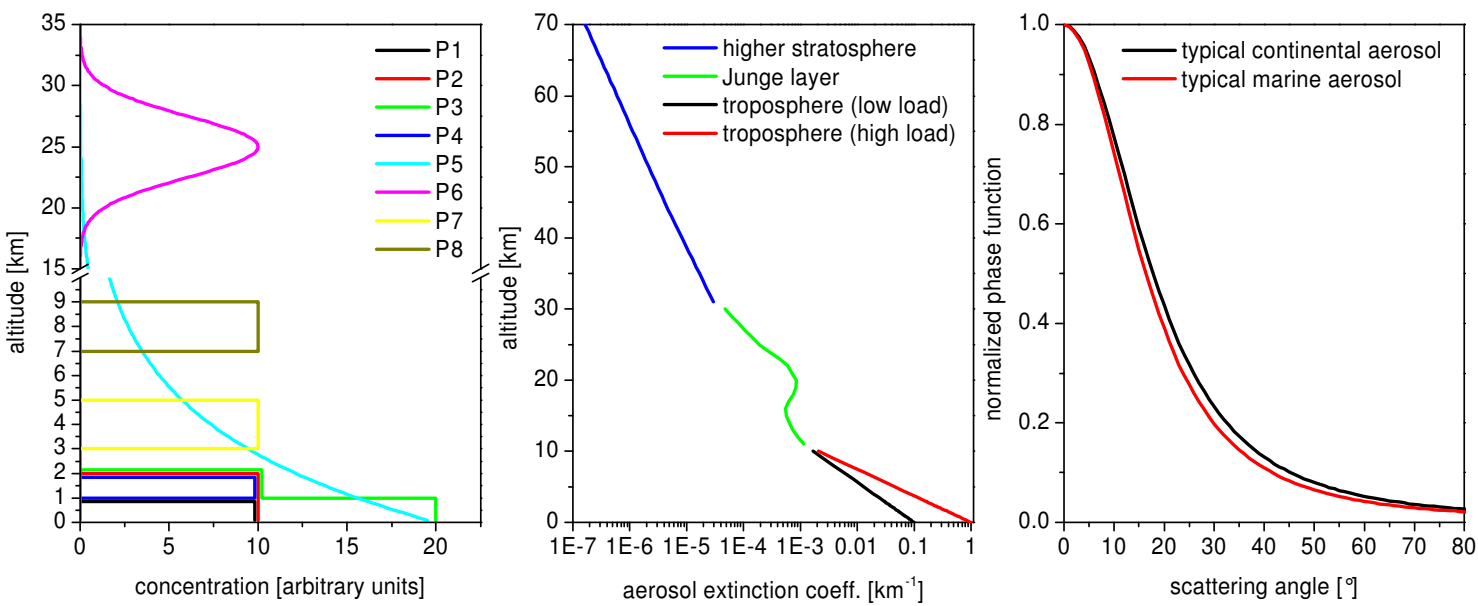

Fig. 2. Profile shapes of test profiles P1-P8 (left), aerosol profile shapes (centre) and aerosol scattering phase functions (right) used for this study (see text).

(von Friedeburg, 2003) which includes multiple Rayleigh and Mie scattering, the effect of surface albedo, refraction, and full spherical geometry. It relies on input data including pressure and temperature profiles, ground or cloud albedo, aerosol profiles and aerosol scattering phase functions as well as profiles of strong molecular absorbers like ozone. Air mass factors and other parameters like the number of scattering events or the altitude of the last scattering event are then calculated for various assumed profiles of the respective absorbers.

The radiative transfer may vary significantly for different angles $\alpha, \vartheta$ or $\phi$, therefore radiative transfer calculations were performed to quantify the influence of the above parameters. In particular the behaviour of AMF's as a function of elevation angle, solar zenith angle, solar azimuth angle, ground albedo, and aerosol load was studied for several idealised trace gas profiles (see Table 2 and left panel of Fig. 2). We assumed constant trace gas concentrations $c$ in the 0 $1 \mathrm{~km}$ and $0-2 \mathrm{~km}$ layers of the atmosphere for the first four profiles (designated P1 through P4). We also investigated four further profiles for comparison, one of oxygen dimers $\left(\mathrm{O}_{4}\right)$ with $c \propto c\left(\mathrm{O}_{2}\right)^{2}(\mathrm{P} 5)$ and a stratospheric profile (P6, centred at $25 \mathrm{~km}$ with a FWHM of $10 \mathrm{~km}$ ) as well as two free tropospheric profiles ( $c$ constant at $5 \pm 1 \mathrm{~km}$ and $8 \pm 1 \mathrm{~km}$, respectively).

The dependence of the AMF for an absorber in the stratosphere and the comparison with an absorber confined to the boundary layer has already been discussed by Hönninger and Platt (2002) for the example of bromine oxide (BrO) in the Arctic boundary layer. The dependence on the solar azimuth angle $\phi$ was shown to be small both, for the stratospheric as well as for the boundary layer case. A significant dependence appears only for high solar zenith angles $\left(\vartheta>80^{\circ}\right)$.

The air mass factors in the sensitivity studies described below were calculated for the following set of parameters:

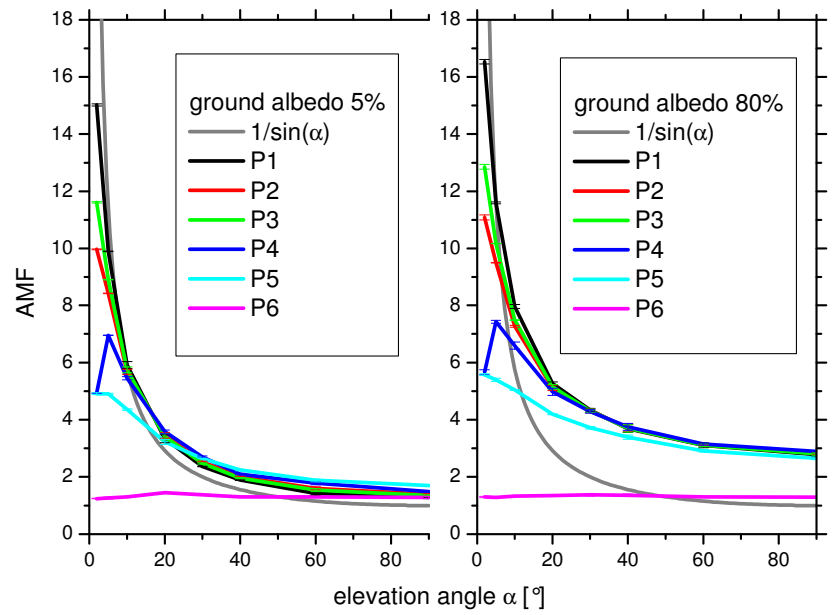

Fig. 3. AMF dependence on the viewing direction (elevation angle $\alpha$ ) for the profiles P1-P6 (see Table 2) for 5\% ground albedo (left) and $80 \%$ albedo (right), respectively. Calculations were performed for a wavelength of $352 \mathrm{~nm}, 30^{\circ}$ Solar zenith angle, and assuming a pure Rayleigh case for the troposphere. For the stratosphere (i.e. above $10 \mathrm{~km}$ ) the standard aerosol scenario (Fig. 2, centre panel) was assumed. The error is the intensity weighted standard deviation of the AMF averaged over the modelled photon paths. The $1 / \sin (\alpha)$ approximation is indicated for reference.

Wavelength $\lambda=352 \mathrm{~nm}$, Telescope elevation angles $\alpha=2^{\circ}$, $5^{\circ}, 10^{\circ}, 20^{\circ}, 30^{\circ}, 40^{\circ}, 60^{\circ}, 90^{\circ}$, relative azimuth $\phi=90^{\circ}$, except for the study of the azimuth dependence, solar zenith angle $\vartheta=30^{\circ}$, except for the study of the SZA dependence. The vertical grid size $h$ for the horizontal layers was $h=100 \mathrm{~m}$ between 0 and $3 \mathrm{~km}, h=500 \mathrm{~m}$ between 3 and $5 \mathrm{~km}$ and $h=1 \mathrm{~km}$ above $5 \mathrm{~km}$ up to the top of the model atmosphere at $70 \mathrm{~km}$. A standard atmospheric scenario (US standard atmosphere) for temperature, pressure and ozone was used and 
Table 4. Summary of instrumental specifications for measurements referred to in this study.

\begin{tabular}{|c|c|c|c|c|c|c|}
\hline Field study & Focus & Instrument type & Spectrometer & \multicolumn{2}{|l|}{ Detector } & Spectral range $[\mathrm{nm}]$ \\
\hline ALERT2000 & Arctic BL BrO & scanning & Acton Research SP500 & \multicolumn{2}{|c|}{ Hamamatsu 1024 pixel PDA ${ }^{1}$} & $320-400$ \\
\hline ANT XVIII/1 & $\mathrm{MBL} \mathrm{BrO}, \mathrm{NO}_{2}$ & scanning & Acton Research SP500 & \multicolumn{2}{|c|}{ Hamamatsu 1024 pixel PDA ${ }^{1}$} & $320-400$ \\
\hline HudsonBay01 & Arctic BL BrO & $\begin{array}{l}\text { scanning } \\
\text { LP-DOAS }\end{array}$ & $\begin{array}{l}\text { Acton Research SP275 } \\
\text { Acton Research SP500 }\end{array}$ & \multicolumn{2}{|c|}{$\begin{array}{l}\text { Hamamatsu } 1024 \text { pixel PDA } \\
\text { Hamamatsu } 1024 \text { pixel PDA }\end{array}$} & $\begin{array}{l}319-381 \\
295-375\end{array}$ \\
\hline ANT XIX/1 & $\begin{array}{l}\mathrm{MBL} \mathrm{BrO}, \mathrm{NO}_{2} \\
\mathrm{NO}_{2}, \mathrm{O}_{4}\end{array}$ & $\begin{array}{l}\text { simultaneous } \\
\text { scanning }\end{array}$ & $\begin{array}{l}\text { Acton Research SP300i } \\
\text { OceanOptics USB2000 }\end{array}$ & \multicolumn{2}{|c|}{$\begin{array}{l}\text { Andor } 1024 \times 256 \text { pixel CCD } \\
\text { Sony ILX511 } 2048 \text { pixel CCD }\end{array}$} & $\begin{array}{l}323-460 \\
396-704\end{array}$ \\
\hline BAB II 2002 & $\mathrm{NO}_{2}$ from traffic & simultaneous & Acton Research AM505 & \multicolumn{2}{|c|}{ EG\&G $1024 \times 256$ pixel $\mathrm{CCD}^{3}$} & $420-450$ \\
\hline Montserrat02 & volcanic $\mathrm{BrO}, \mathrm{SO}_{2}$ & scanning & OceanOptics USB2000 & \multicolumn{2}{|c|}{ Sony ILX511 2048 pixel CCD } & $251-402$ \\
\hline Uyuni2002 & $\mathrm{BrO}$ from salt & scanning & OceanOptics USB2000 & \multicolumn{2}{|c|}{ Sony ILX511 2048 pixel CCD } & $270-412$ \\
\hline Field study & Spectral resolution $[\mathrm{nm}]$ & ] Time resolution & Elevation angles $\left[{ }^{\circ}\right]$ & & \multicolumn{2}{|l|}{ Reference } \\
\hline ALERT2000 & 0.5 & $5 \min \ldots 1 \mathrm{~h}$ & $5,10,20,90,(40,60)$ & & \multicolumn{2}{|c|}{ Hönninger and Platt 2002, Hönninger 2002} \\
\hline ANT XVIII/1 & 0.3 & $5 \min \ldots 1 \mathrm{~h}$ & $5,10,20,40,60,90$ & & \multicolumn{2}{|c|}{ Leser et al. 2003, Leser 2001} \\
\hline HudsonBay01 & $\begin{array}{l}0.3 \\
0.5\end{array}$ & $\begin{array}{l}5 \min . . .30 \mathrm{~min} \\
1 \mathrm{~min} . .1 \mathrm{~h}\end{array}$ & $5,10,20,90$ & & \multicolumn{2}{|c|}{ Hönninger et al. 2004a } \\
\hline ANT XIX/1 & $\begin{array}{l}0.6 \ldots 0.9 \\
1.6\end{array}$ & $\begin{array}{l}10 \mathrm{~min} \\
10 \mathrm{~min} . .1 \mathrm{~h}\end{array}$ & $\begin{array}{l}2,5,10,20,45,90 \\
2,5,10,20,70\end{array}$ & & \multicolumn{2}{|l|}{ Bossmeyer 2002} \\
\hline BAB II 2002 & 0.25 & $1 \mathrm{~min}$ & $0.8,1.6,2.4,0.7,1.4,2.0$ & & \multicolumn{2}{|l|}{ von Friedeburg 2003} \\
\hline Montserrat 02 & 0.7 & $1 \mathrm{~min} . . .10 \mathrm{~min}$ & $10,15,20,30,40,50,60$ & $, 70,80,90$ & \multicolumn{2}{|c|}{ Bobrowski et al. 2003, Bobrowski 2002} \\
\hline Uyuni2002 & $0.6 \ldots 0.7$ & $1 \mathrm{~min} . .5 \mathrm{~min}$ & $5,10,20,90$ & & \multicolumn{2}{|c|}{ Hönninger et al. 2004b } \\
\hline
\end{tabular}

${ }^{1}$ S5931 ${ }^{2}$ DV420-OE ${ }^{3} 1530-\mathrm{P}-1024 \mathrm{~S}$

interpolated to match the vertical grid of the model. The parameters used for the following simulations are summarized in Table 3.

In order to characterise the role of aerosols, the following scenarios were modelled: Above $10 \mathrm{~km}$ a standard aerosol load from a chemical model scenario (Hendrick, pers. comm. 2003 ) with $\varepsilon_{M} \sim 10^{-3} \mathrm{~km}^{-1}$ at $10 \mathrm{~km}$ was selected. Below $10 \mathrm{~km}$, where the aerosol load becomes important for tropospheric absorbers due to its influence on the radiative transfer, 3 cases were chosen:

1. "Pure Rayleigh" case, no tropospheric aerosols.

2. "Low aerosol" load, with an extinction coefficient at $0 \mathrm{~km}$ altitude of $\varepsilon_{M}=0.1 \mathrm{~km}^{-1}$, and linear interpolation of $\left(\log \varepsilon_{M}\right)$ between the ground and the stratosphere (see Fig. 2, centre panel).

3. "High aerosol" load with extinction coefficient at $0 \mathrm{~km}$ of $\varepsilon_{M}=1 \mathrm{~km}^{-1}$, and linear interpolation of $\left(\log \varepsilon_{M}\right)$ between the ground and the stratosphere.

4. Two scattering phase functions were distinguished for the cases 2 and 3: (a) typical continental aerosol and (b) typical marine aerosol (see Fig. 2 right panel).
The single scattering albedo of the aerosols was set to 1 for simplicity. All model runs were performed for two ground albedo values of $5 \%$ and $80 \%$, respectively.

4.1 The dependence of the AMF on the observation geometry

In order to demonstrate the sensitivity of MAX-DOAS towards various vertical trace gas profiles we first focus on a simple atmospheric scenario and discuss the dependence of the AMF on the viewing direction (parameterised as elevation angle $\alpha$ ) for several vertical trace gas profiles. In Fig. 3 the modelled air mass factors for the profile shapes P1-P6 are plotted as a function of the viewing direction for the pure Rayleigh case and low (left) and high (right) ground albedo.

The AMF is strongly dependent on the viewing direction (elevation angle $\alpha$ ) for the profiles, where the absorber is close to the ground. The AMF for the profiles extending to the ground (P1, P2, P3, P5) increases continuously when the elevation angle decreases. This effect can still be understood in the geometric approximation discussed in Sect. 3. The viewing direction determines the absorption path length, which decreases continuously for P1, P2, P3 and P5 when $\alpha$ increases. The increase is strongest for the lowest profile 

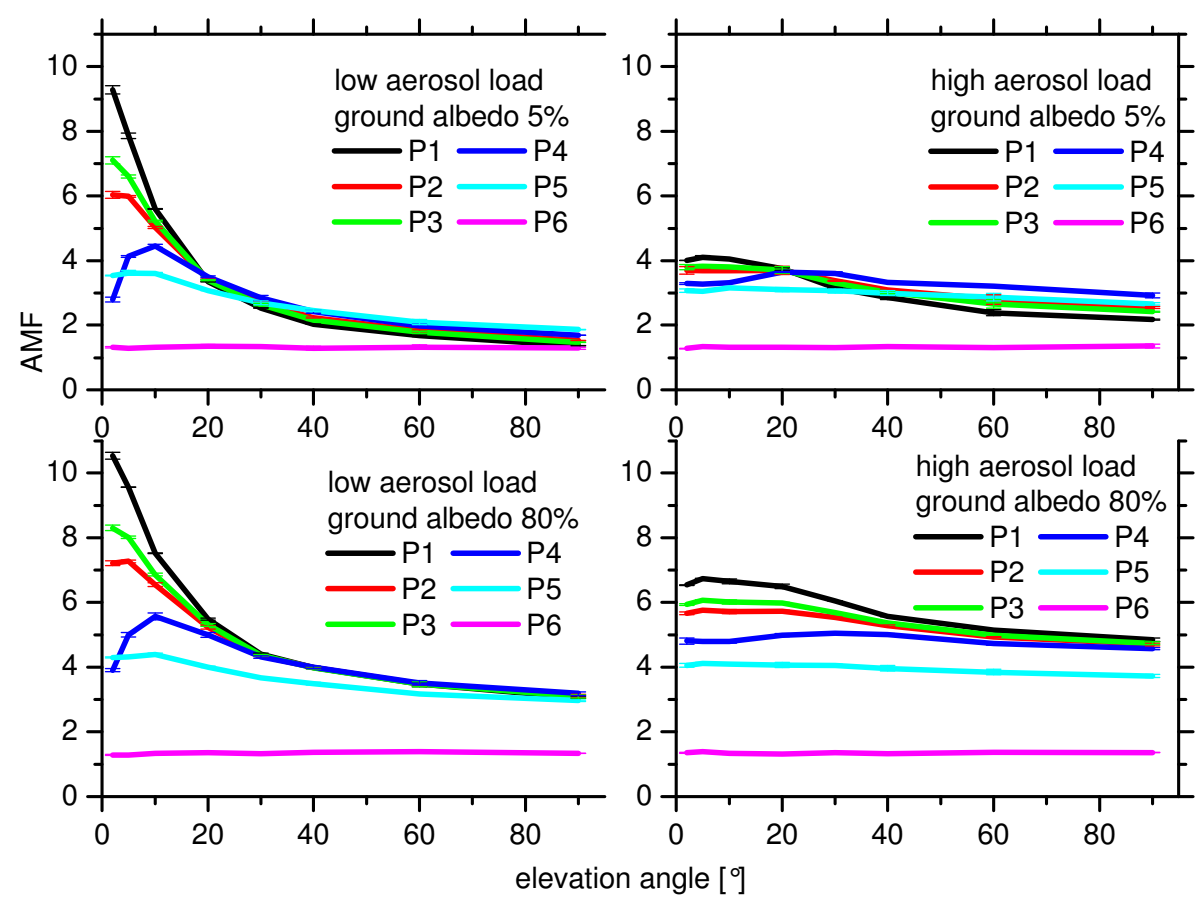

Fig. 4. AMF as a function of viewing direction (elevation angle $\alpha$ ) for P1-P6 for low (left column) and high (right column) aerosol load and for 5\% (top panels) and 80\% (bottom panels) ground albedo, respectively. Calculations were performed for the same scenario as in Fig. 3 , but for typical continental aerosol (left panels: low aerosol load, right panels: high aerosol load, see Fig. 2), differences to marine aerosol are discussed below.

P1 and less strong for the profiles extending to higher altitudes. The maximum AMF for the elevated layer profile P4 appears at $\alpha=5^{\circ}$ and AMF decreases for smaller and larger $\alpha$. Simply speaking the instrument looks "below" the layer at $\alpha<5^{\circ}$. In contrast to that the AMF is almost independent of the viewing direction for the stratospheric profile P6. The characteristic altitude that determines how the AMF depends on the viewing direction is the mean last scattering altitude (LSA, see below).

\subsection{Aerosol and albedo dependence}

Aerosol load and scattering properties as well as the surface albedo play a significant role in the radiative transfer, especially in the lower troposphere. In Fig. 4 the AMF dependence on the observation elevation angle is shown again for the different profile shapes (P1-P6), this time not for the pure Rayleigh troposphere, but for two different aerosol scenarios (high and low tropospheric load) as well as for high and low ground albedo. The calculations assuming low aerosol load are not different in general shape from the Rayleigh case, however the absolute values of the AMF are considerably smaller at elevation angles of $10^{\circ}$ and lower. In contrast, at high aerosol load the increase of the AMF at lower elevation angles becomes much weaker, and the variation of the AMF with elevation angle becomes much less pronounced.

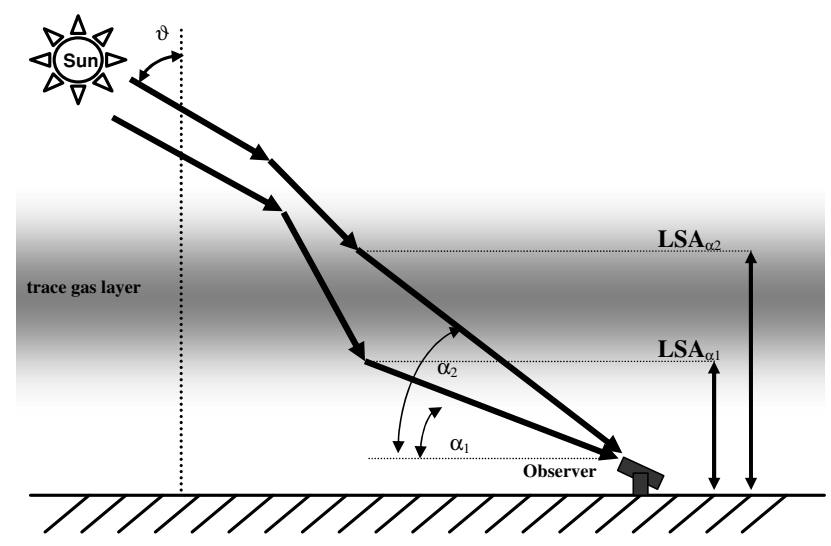

Fig. 5. The Last Scattering Altitude LSA: for low elevation angles, the mean free path in the viewing direction is shorter due to higher density and/or aerosol load. This can result in the slant path through absorbing layers at higher altitudes being shorter for lower elevation angles than for higher ones.

The air mass factors at low elevation angles are generally smaller for increased aerosol load compared to the Rayleigh case, while they increase at high elevation angles. However the increase of the AMF with smaller elevation angles remains very similar for the profiles extending to the ground (P1-P3) in the low aerosol load scenario. It can already 


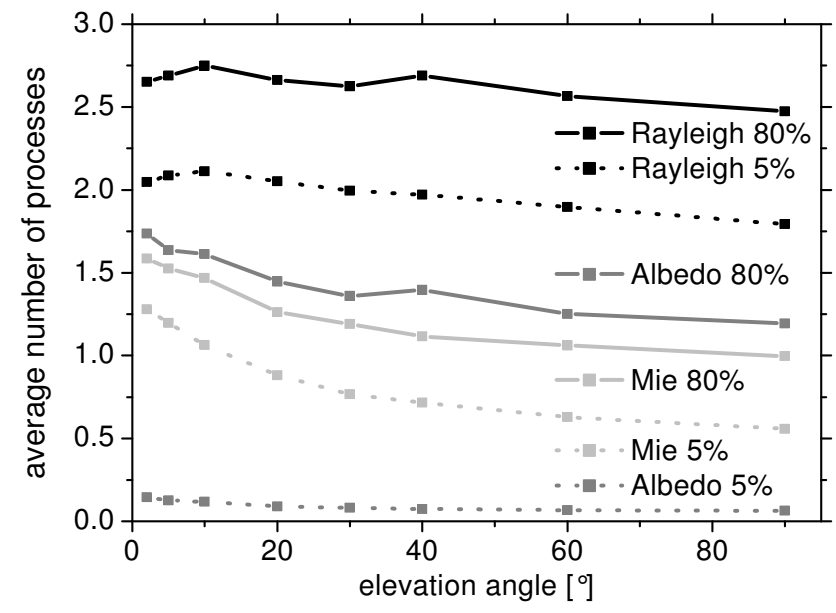

Fig. 6. Number of Rayleigh, ground (albedo), and Mie scattering events as a function of elevation angle for the typical rural low aerosol scenario and 5\% (dashed lines) and 80\% (drawn lines) ground albedo, respectively.

be seen in the low aerosol load scenario, that the AMF is strongly decreasing (compared to the Rayleigh case) for the profiles extending to higher levels, e.g. P4 and P5. This appears to be due to the shorter mean free path of photons due to the aerosol extinction. Therefore, the absorption path in the lowest atmospheric layers is shorter in these cases and a more vertical path in the higher layers is probable as is sketched in Fig. 5. This also explains why deviations from the AMF behaviour based on simple geometric assumptions (as sketched in Fig. 1) become more and more obvious for higher aerosol loads.

This effect is even stronger for the high aerosol load scenario due to shorter mean free paths and correspondingly lower scattering altitudes near the ground. The maximum of the AMF curve can shift towards higher elevation angles by as much as $40^{\circ}$ (e.g. the lifted layer profile P4 in Fig. 4, high aerosol, $80 \%$ ground albedo case). However, shorter mean free paths also lead to a higher average number of scattering events (see Fig. 6), thus reducing the differences between the various viewing directions in a way, that differences might not be significant anymore in measurements.

Two different aerosol phase functions, continental and maritime (see Fig. 2) were investigated, results are shown in Fig. 7. The phase function for the marine aerosol (Fig. 2) indicates slightly favoured forward scattering compared to the continental case. However, no significant differences between the two aerosol types can be seen here, since the phase functions are quite similar.

The effect of higher albedo generally enhances the AMF for the profiles extending to the ground (P1-P3), because longer absorption paths in the lowest layers are favoured by scattering at the ground. Since the effect of the higher albedo increases all AMF's by almost the same amount, it has no

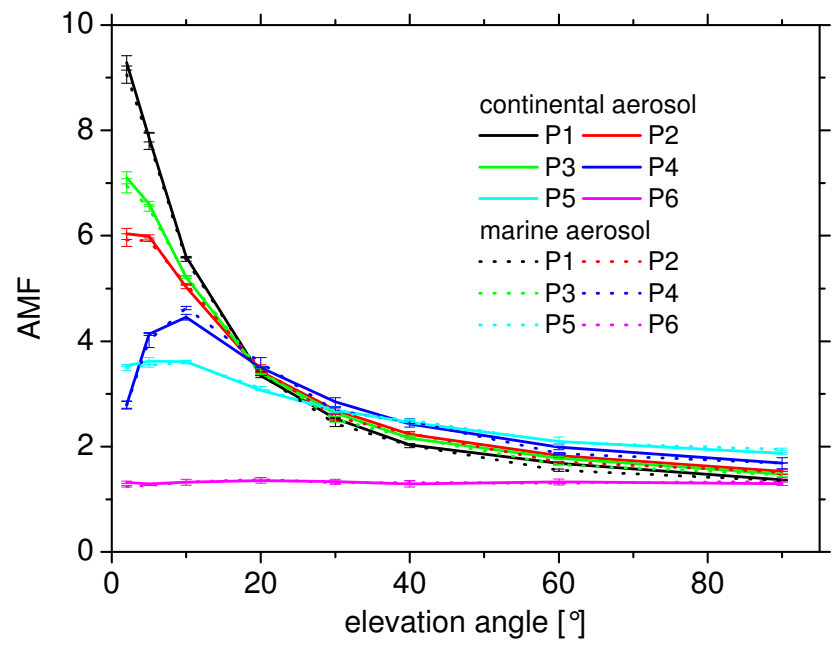

Fig. 7. Effect of different aerosol types on the AMF, drawn lines indicate continental background aerosol (same as "low aerosol load" in Fig. 4). Only small differences result from different scattering phase functions.

significant effect on the elevation angle dependencies, and rather constitutes an offset.

As mentioned above, another parameter that determines the sensitivity of MAX-DOAS towards absorbers with different profile shapes is the number of scattering events that photons undergo on average prior to being detected by the MAX-DOAS instrument. Figure 6 shows the contribution of the different scattering processes as a function of elevation angle for the typical low aerosol scenario for both low (5\%) and high (80\%) ground albedo.

It can clearly be seen that a higher ground albedo strongly increases the overall number of scattering events compared to the low albedo case. The probability of Mie and ground scattering processes increases, especially for the low elevation angles. Since both scattering processes take place largely at or close to the ground, this finding is not surprising. However, the specific behaviour and the influence on the respective air mass factors can only be modelled properly using an RTM. The albedo increase from $5 \%$ to $80 \%$ has also a significant effect on the number of Rayleigh scattering events, since more light reaching the ground is reflected and can undergo more scattering processes.

\subsection{The Last Scattering Altitude (LSA)}

A key parameter that governs the sensitivity of MAX-DOAS measurements towards different vertical profiles of absorbers is the altitude of the last scattering event (last scattering altitude, LSA, see also Fig. 5) before the photon finally reaches the MAX-DOAS instrument. The LSA dependence on the viewing direction is shown in Fig. 8. As expected, the LSA becomes smaller for the lower elevation angles. This can lead to the observed behaviour of the AMF with a maximum 


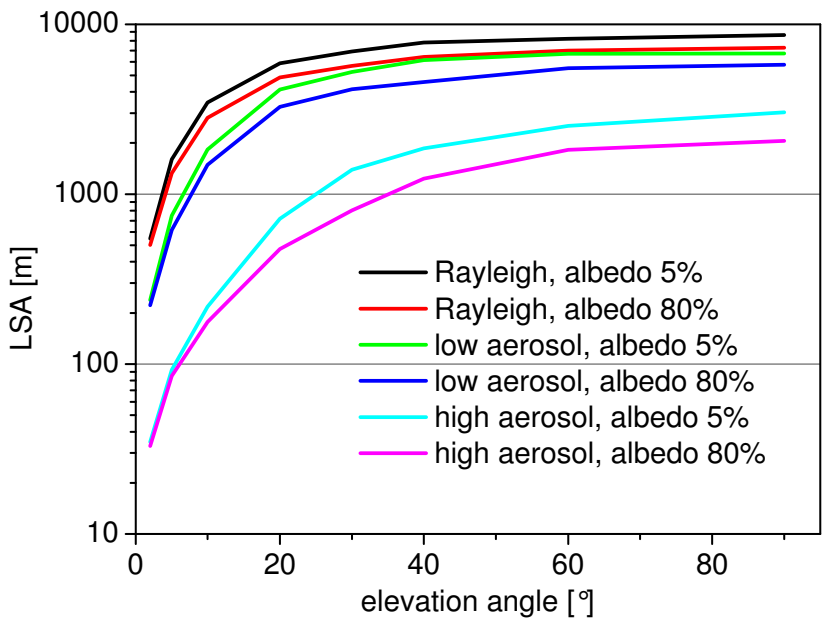

Fig. 8. Last scattering altitude (LSA) for pure Rayleigh, low and high aerosol load scenarios (see Fig. 4) and both, 5\% and 80\% albedo. The LSA is generally below $1 \mathrm{~km}$ for the lowest elevation angle and above $1 \mathrm{~km}$ for the highest elevation angles, especially for zenith viewing direction.

between $10^{\circ}$ and $20^{\circ}$, and smaller AMF for the very low elevation angles (e.g. for P3). The LSA effectively determines the length of the last section of the path taken by the photons through the lowest atmospheric layer at the observation elevation angle $\alpha$.

This analysis explains the following effects:

- For profiles extending to the ground and with vertical extensions comparable to the LSA, such as P1-P3, the AMF is generally smaller than estimated from the geometrical $(1 / \sin \alpha)$-approximation.

- For profiles elevated from the ground and/or with a significant fraction of the profile above the respective LSA, such as P4 or P5, the AMF has a maximum at an elevation angle, where the mean free path still allows transecting the absorbing layer on a long slant path. AMF's decrease again for the very small elevation angles due to light paths being shorter in the layers with high absorber concentrations.

- For stratospheric profiles, such as P6, the last scattering processes near the ground cannot influence the AMF since the absorber is only present at high altitudes. Therefore, the AMF for stratospheric absorbers is largely independent of the viewing direction.

\section{4 "Box" air mass factors}

Box AMF's are a measure of the light path enhancement compared to a vertical path in a given height interval. In

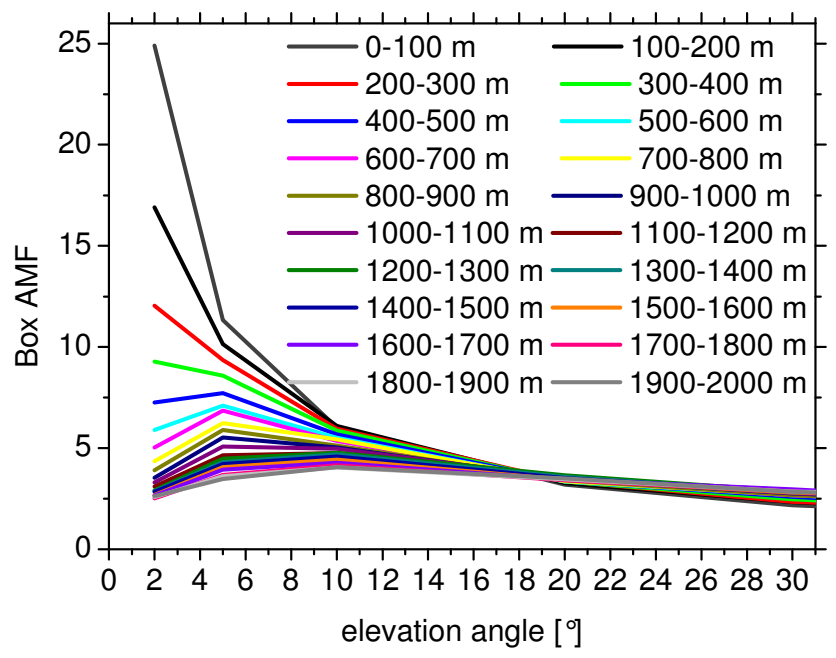

Fig. 9. Box AMF for the model layers below $2 \mathrm{~km}$ altitude. The sensitivity towards the lowest layers changes strongly for elevation angles below $10^{\circ}$, for elevation angles smaller than $5^{\circ}$ the sensitivity already decreases for layers above $400 \mathrm{~m}$ altitude.

the case of weak absorption and a horizontally homogeneous atmosphere the Box AMF can be expressed as:

$A_{\mathrm{Box}}=\frac{\int_{\text {Box }} d s}{\int_{\text {Box }} d z}$,

with the actual light path $s$ and the vertical path $z$.

Box Air Mass Factors modelled for different viewing directions (elevation angles) therefore serve as a measure of the sensitivity of a particular viewing direction towards an absorber being present in a specific vertical "box" (or layer). Therefore, Box AMF's provide a criterion for determining the sensitivity of MAX-DOAS for different shapes of vertical profiles.

Figure 9 shows modelled Box AMF's for assumed trace gas layers of $100 \mathrm{~m}$ thickness located below $2 \mathrm{~km}$ altitude. Variations of the Box AMF's are clearly strongest towards the surface for the very low elevation angles. Consequently MAX-DOAS should be very sensitive to different profile shapes in this altitude range. The general trend for elevation angles smaller than $5^{\circ}$ of increasing Box AMF with decreasing $\alpha$ is only observed for layers below $400 \mathrm{~m}$ altitude. Above this altitude, the trend reverses and Box AMF's decrease.

This confirms that a good knowledge of the aerosol load of the probed airmass is important in order to choose the correct $\mathrm{AMF}$ and thus to derive quantitative trace gas vertical columns $V$. In fact, some information about the vertical trace gas distribution can be gained from an analysis of the variation of the observed slant column with the elevation angle, as explained above; the vertical thickness $D$ of a trace gas layer can be derived. This information can be used to infer the average trace gas concentration in the layer. 


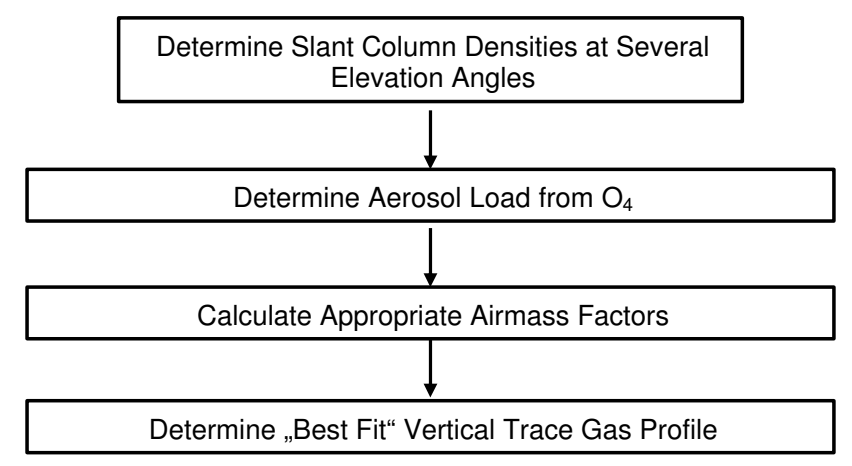

Fig. 10. Diagram of a MAX-DOAS evaluation procedure including the determination of the aerosol load from $\mathrm{O}_{4}$ observations.

4.5 $\mathrm{O}_{4}$ profile and measurements as good indicator for the aerosol load

The observation of the slant columns of oxygen dimers (and other species with known atmospheric distribution, e.g. $\mathrm{O}_{2}$ ) offers in principle an excellent opportunity to determine the aerosol load of the atmosphere. The atmospheric $\mathrm{O}_{4}$ concentration profile is well known; it is essentially given by $c_{\mathrm{O}_{4}}(z) \propto c_{\text {air }}^{2}(z)$ with a known dependency of the air density $c_{\text {air }}$ on temperature and barometric pressure. The measured set of $\mathrm{O}_{4}$ slant column densities (for a series of elevation angles e.g. from $2^{\circ}$ to $90^{\circ}$ ) can then be compared to a series of calculated $\mathrm{O}_{4}$ SCD's (for the temperature and pressure profile as recorded during the measurement), where the aerosol load should be varied until best agreement is reached. As outlined in Fig. 10 this aerosol load can then be used to calculate a further series of "Box" AMF's which, together with the slant column densities of the trace gases under investigation, can be used as input for a linear equation system. Alternatively, the AMF for several test profiles can be calculated and the "best fit" vertical trace gas profile (of e.g. the type P1...P4) can be chosen.

\subsection{Azimuth dependence of the AMF}

In the case of horizontally inhomogeneous trace gas distributions the observation azimuth angle is clearly of importance and has to be determined in each individual case. For horizontally homogeneous distributions a dependence of the air mass factors on the relative azimuth angle between the sun and the viewing direction can arise from the shape of scattering phase functions for the respective scattering processes. Therefore, light paths taken by photons at different relative azimuth angles may be different resulting in different elevation angle dependence of the AMF and possible results on MAX-DOAS measurements. This effect is expected to be higher for large SZA since only then can one expect significant influence on the radiative transfer at low altitudes which is most important for MAX-DOAS measurements (Hönninger and Platt, 2002).

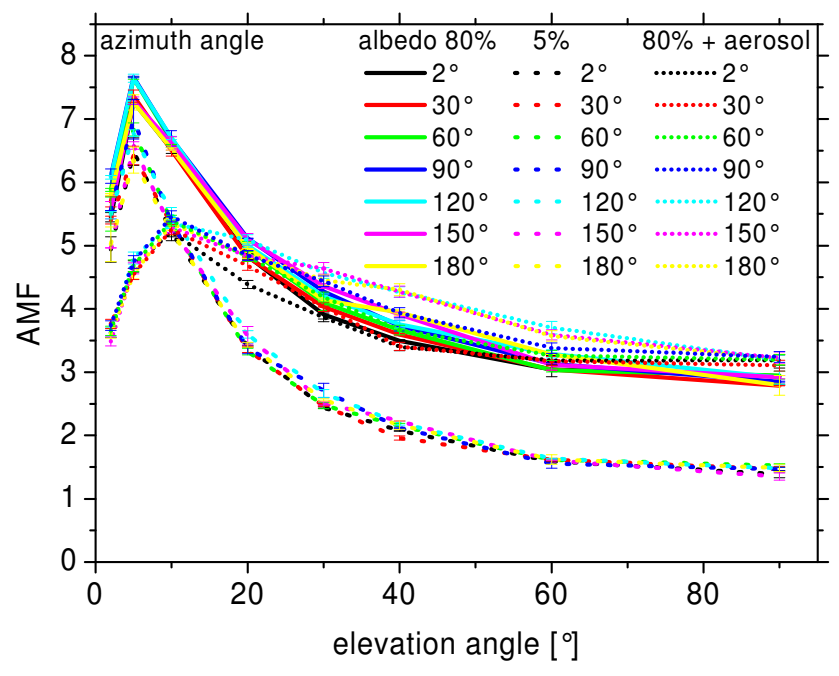

Fig. 11. Azimuth-dependence of the AMF for $30^{\circ} \mathrm{SZA}$ and profile P4 (trace gas layer at $1-2 \mathrm{~km}$ altitude). For relative azimuth angles between $2^{\circ}$ (looking almost towards the sun) and $180^{\circ}$ (looking away from the sun) only a small effect increasing with ground albedo and aerosol load can be seen. Calculations were performed for a ground albedo of $80 \%$ and $5 \%$ (cf. Fig. 3) in the Rayleigh case (in the troposphere) and for $80 \%$ ground albedo in the low aerosol case (cf. Fig. 4).

Figure 11 shows the small effect of the relative azimuth angle for a SZA of $30^{\circ}$ and the profile P4. No significant influence on the general elevation angle dependence of the AMF is seen. However, the small azimuth dependence is found to increase with ground albedo and tropospheric aerosol load.

\subsection{SZA dependence of the AMF}

The solar zenith angle (SZA) is the most important parameter when characterizing air mass factors for stratospheric absorbers. In Fig. 12 the strong dependence of the AMF on the SZA can be seen for the stratospheric profile P6, whereas the viewing direction only plays an insignificant role. In contrast to that for the tropospheric profiles (e.g. $\mathrm{P} 2$ and the $\mathrm{O}_{4}$ profile P5) the SZA dependence of the AMF is minor and only significant at large SZA. Here, the viewing direction (elevation angle) is the parameter that governs the AMF as discussed above.

The SZA dependence of the AMF for the different profiles can be best understood from the altitudes of the first and last scattering event (FSA, LSA, respectively). These parameters can serve as a proxy for the general pattern of the light path taken by the registered photons. Figure 13 shows both first and last scattering altitude as a function of SZA. While the FSA strongly increases towards high SZA, the LSA is largely independent of SZA. As long as the FSA is below or still within an absorber profile (which is the case for the $\mathrm{O}_{4}$ profile P5 up to a higher SZA than is the case for P2), the first light path segment (above FSA) increases strongly with 

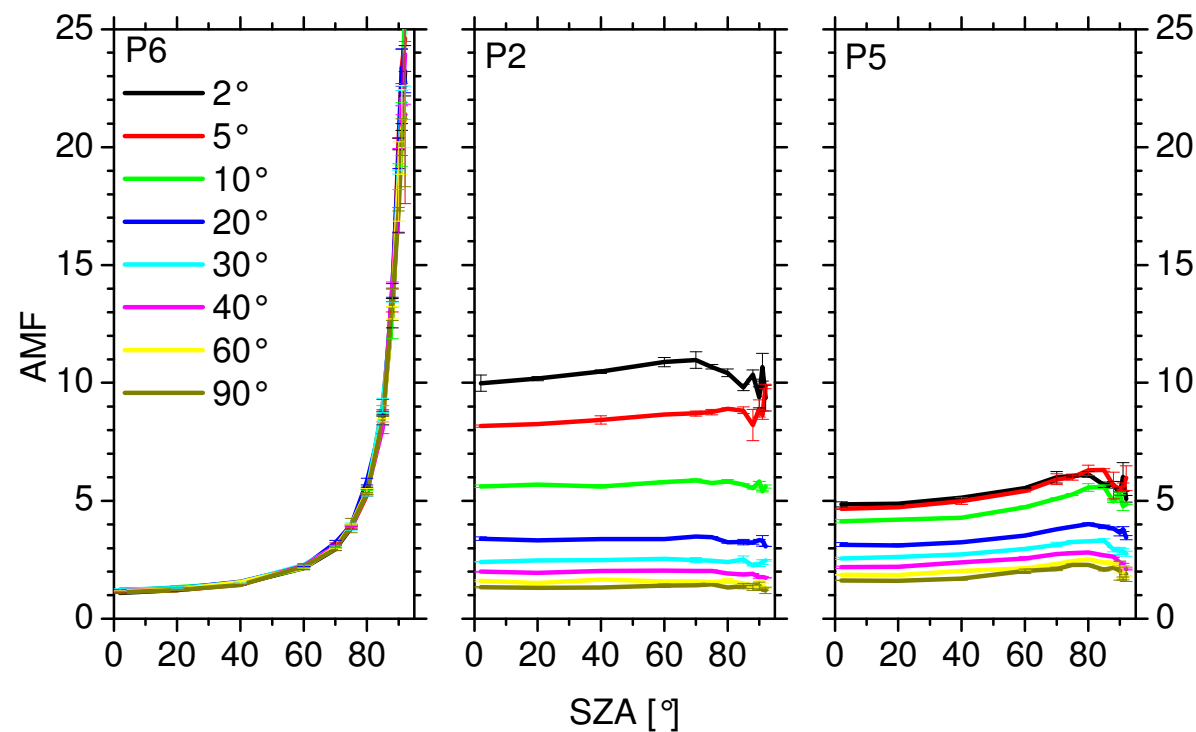

Fig. 12. Solar Zenith angle (SZA) - dependence of the AMF for the typical stratospheric profile P6 and the boundary layer profile P2 as well as the $\mathrm{O}_{4}$ profile $\mathrm{P} 5$ for comparison. The expected strong dependence is observed for the stratospheric absorber, with no significant dependence on the viewing direction. In contrast to that for the tropospheric profiles P2 and P5 significant differences for the various viewing directions can be seen, whereas the SZA dependence is significant only at higher SZA (i.e. $>70^{\circ}$ ).

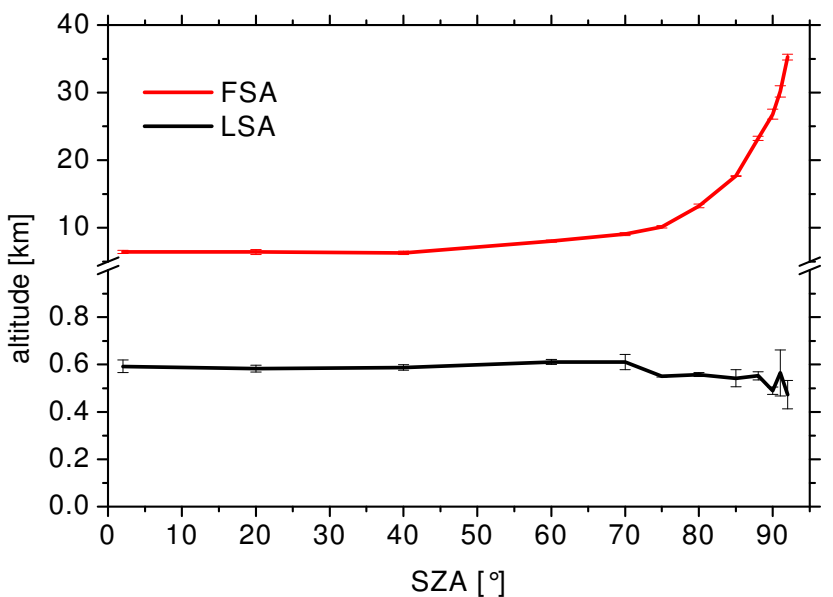

Fig. 13. First and last scattering altitude for the $2^{\circ}$ elevation angle. The FSA strongly depends on the SZA, whereas the LSA is largely independent of the SZA. Note the axis break at $1 \mathrm{~km}$ altitude and the expanded y-scale below.

SZA (approximately according to $1 / \cos (\mathrm{SZA})$ ). As soon as the FSA is above the absorber, the first slant path segment does not increase the AMF and therefore the AMF dependence on the SZA disappears.

\subsection{Profiles of free tropospheric absorbers}

As discussed above, ground-based MAX-DOAS can clearly distinguish between stratospheric profiles (e.g. P6) and various tropospheric profiles (P1-P5). However, the limitation of
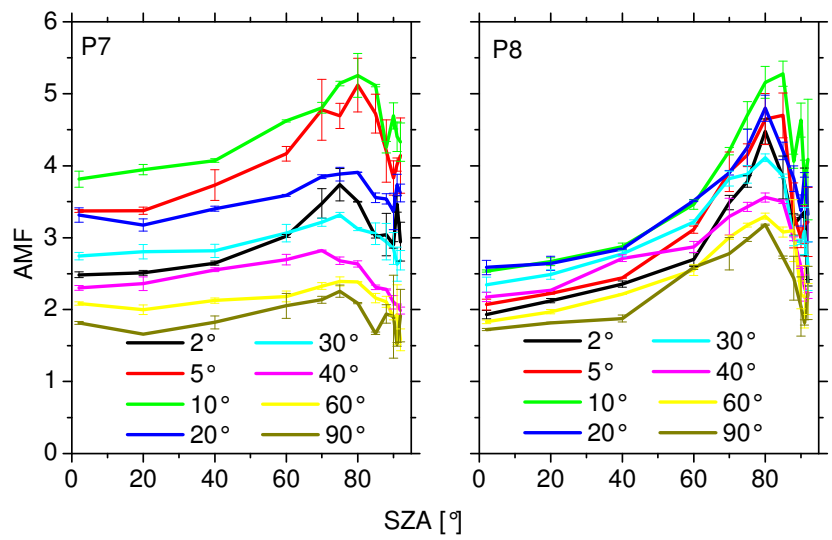

Fig. 14. AMF as a function of SZA for the "free tropospheric profiles" P7 and P8 with the elevation angle as parameter (shown in different colors). The SZA dependence is smaller than for the stratospheric profile $\mathrm{P} 6$, but much stronger than for the lower tropospheric profiles P1-P5.

the sensitivity towards profiles at higher altitudes remains to be investigated. Figure 14 shows the SZA dependence of the AMF for two layers with constant trace gas concentration in the free troposphere (P7 and P8, see Table 2 for definition).

The SZA dependence of the profiles P7 and P8 is not as strong as for the stratospheric profile P6, but clearly more visible than for the boundary layer profiles or the $\mathrm{O}_{4}$ profile P1-P5. On the other hand, the differences between the various elevation angles (shown as different colours in Fig. 14) are much smaller than for the lower tropospheric profiles. 


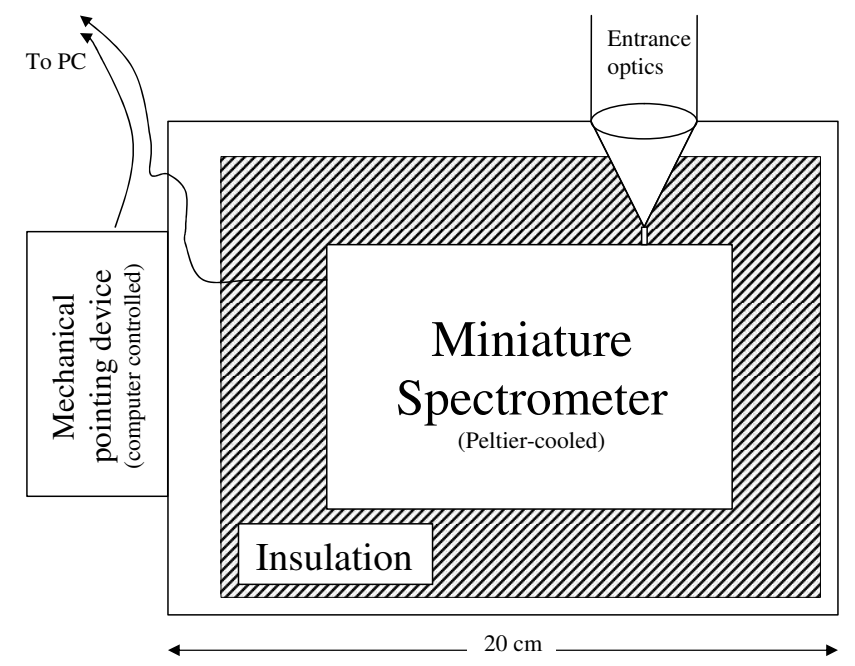

Fig. 15. Outline of the Mini-MAX-DOAS instrument. A miniature spectrometer is cooled and temperature stabilized by a 2 stage Peltier cooler. The built-in entrance optics (telescope) provide a narrow field of view $\left(<0.5^{\circ}\right)$. The unit can be pointed in various directions by computer control.

Differences for various elevation angles are still significant in MAX-DOAS measurements for a free tropospheric profile like P7, however, for profile P8 the small differences between the viewing directions are even more difficult to measure and to distinguish from measurement errors, modelling noise and from the variability of the trace gas concentration.

\section{Practical realization of MAX-DOAS systems}

As described above MAX-DOAS systems have been employed for the measurement of atmospheric trace gases by several authors (see Table 1). A number of technical requirements have to be fulfilled by MAX-DOAS instruments. Besides sufficient spectral resolution (around $0.5 \mathrm{~nm}$ in the near UV) in particular a sufficiently small field of view of the telescope (typically $<1^{\circ}$ ) is required, and of course the instrument must allow measurements in different viewing directions. A number of technical approaches have been developed to meet these requirements:

1. Sequential observation at different elevation angles. This approach has the advantage of a relatively simple set-up requiring only one spectrometer and some mechanism for pointing the telescope (or the entire spectrometer-telescope assembly) in the desired directions. It was therefore used in several studies (Hönninger and Platt, 2002; Leser et al., 2003; Bobrowski et al., 2003; Hönninger et al., 2004a; Hönninger et al., 2004b). Disadvantages are that the measurements are not simultaneous, typically a complete cycle encompassing several (usually 4 to
10) observation directions may take 5 to $30 \mathrm{~min}$ (e.g. Hönninger and Platt, 2002). It certainly depends on the respective aim of a field study whether this represents a significant drawback. For example, at high latitudes simultaneity may often not be an issue because the SZA changes only slowly there. In contrast to that the effect of changing SZA and thus the observed stratospheric trace gas column densities is much more pronounced at mid- and low latitudes. However, since the change in SZA can be well described by a simple polynomial fit to the measured time series for each elevation angle, its effect can be removed by interpolating all time series on a common grid prior to further analysis (Leser et al., 2003). On the other hand interpolation can be difficult during periods of rapidly varying radiative transport conditions in the atmosphere, for example varying cloud cover, aerosol load, during sunrise/sunset or on a moving (e.g. airborne) platform. In the latter cases and when high time resolution is required simultaneous observation should be preferred (see below). A scanning instrument also contains mechanically moving parts, which may be a disadvantage in long term operation at remote sites. Very robust, lightweight and small-sized MiniMAX-DOAS instruments have recently been applied for automated operation at remote sites (Galle et al., 2003; Bobrowski et al., 2003; Hönninger et al., 2004b) (see Fig. 15).

2. Simultaneous observation at different elevation angles allows truly simultaneous determination of SCD's at the different elevation angles and thus avoids the problems of set-up 1. Disadvantages here are the larger instrumental requirement, since a spectrometer and a telescope for each of the observation directions is needed. However, recent development of very compact, low cost spectrometer/detector combinations (e.g. Galle et al., 2003; Bobrowski et al., 2003; Hönninger et al. 2004b see Fig. 15) can be of help here. Simultaneous measurements can be realised by installing a set of instruments observing multiple elevation angles from the same location. In case of non-homogeneous trace gas distributions this approach is superior to the scanning method, since additionally scanning the azimuth angle further decreases the time resolution. Alternatively some simplification may come from using spectrometers with two dimensional detectors, (see Fig. 16 and description below) (Heismann, 1996; Wagner et al., 2002; Löwe et al., 2002; Bossmeyer, 2002; Oetjen, 2002; von Friedeburg, 2003; Heckel, 2003).

A severe problem arises, however, if the different instruments are to be ratioed against each other in order to eliminate the solar Fraunhofer structure (see Sect. 2). This proves extremely difficult if different instruments with - in practice - different instrument functions are involved (e.g. Bossmeyer, 2002; von Friedeburg, 2003). 


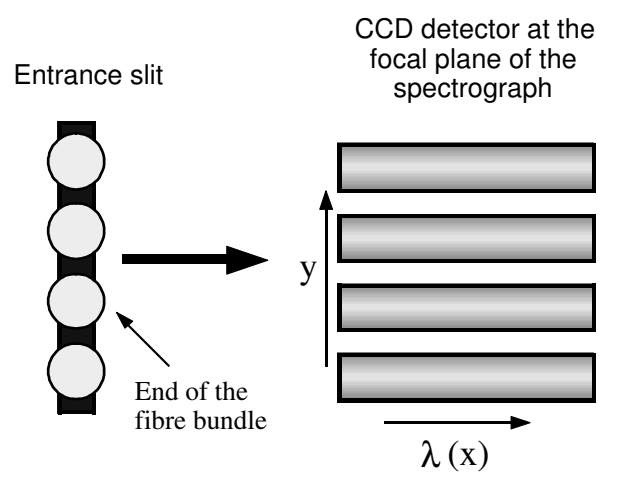

Fig. 16. Two dimensional spectrometer: Orientation of the spectra of the measured light from different viewing angles on the CCD array. The dispersion direction is labeled " $x$ ", thus for each fibre ending at the entrance slit a complete and separate spectrum is generated on the CCD.

Although this can in principle be overcome by "cross convolution" (i.e. convolving each measured spectrum with the instrumental line shape of the respective spectrum it is to be compared with), or by generating difference spectra from FRS, none of these approaches has yet provided the same sensitivity as can be reached with a scanning instrument. Any convolution of measured atmospheric spectra with an instrument function of typically 5-10 detector pixels FWHM reduces the spectral resolution and essentially "smoothes" intensity variations (e.g. spectral features, photon shot noise, detector pixel-to-pixel variability and electronic noise) that are below the spectral resolution (FWHM) of the instrument. This can result in spectral artefacts due to smoothing of noise and thus can affect the quality of the DOAS fit (e.g. Bossmeyer, 2002). While detector pixel-to-pixel variability can largely be removed by correcting with a "white light" spectrum (e.g. from an incandescent lamp), taking these additional spectra regularly comes at the cost of measurement time, additional power requirements and experimental effort. It appears that, given present instrumentation, the highest sensitivity is reached with sequential observation.

3. A solution lies in the combination of techniques 1) and 2 ), i.e. the use of multiple spectrometers (one per observation direction) and moving telescopes (or spectrometer telescope assemblies). While this approach appears to combine the disadvantages of the two above set-ups it also combines their advantages: If each individual instrument sequentially observes at all elevation angles and the observations are phased in such a way that at any given time one instrument observes each observation direction, then indeed not only will simultaneous observation be achieved at each angle, but also each instrument regularly sees the zenith to record a Fraun-

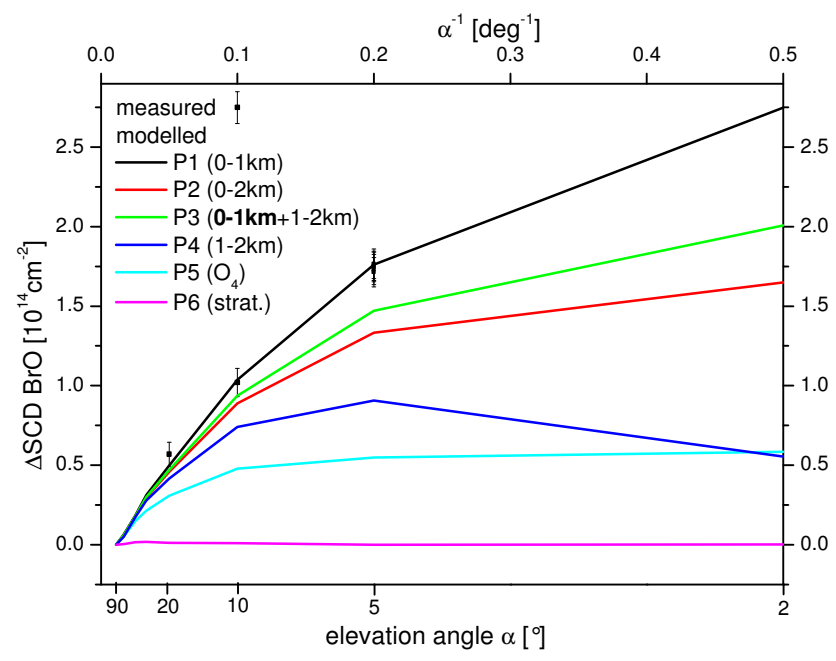

Fig. 17. Comparison of $\Delta$ SCD's measured on 4 May 2000 (15:15 UT-15:40 UT) during the Alert2000 field experiment by Hönninger and Platt (2000) with calculated $\triangle$ SCD's for assumed profile shapes P1-P6 as a function of the elevation angle $\alpha$. For better illustration the $\mathrm{x}$-axis was chosen linear in $\alpha^{-1}$. 4 May 2000 at Alert was characterized by a relatively constant $\mathrm{BrO}$ column (BL$\left.\mathrm{VCD}_{\mathrm{BrO}}=2 \times 10^{13} \mathrm{molec} / \mathrm{cm}^{2}\right)$. Only $\mathrm{P} 1$ is compatible with the measured values.

hofer spectrum for reference. Instruments based on this approach are presently used on cruises of the German research vessel Polarstern (see Leser et al., 2003; Bossmeyer, 2002).

5.1 Spectrometer with two dimensional detector for simultaneous MAX-DOAS observation

In the simultaneous MAX-DOAS version light from several telescopes collecting scattered sunlight at the desired elevation angles is transmitted to the entrance slit of the spectrometer by quartz fibres (see Fig. 16). In order to separate the spectra of the light observed at the different viewing angles two-dimensional CCD arrays are needed as detectors (Heismann, 1996). The light is dispersed in $\lambda$ (x)-direction (Fig. 16) and the different spectra for the light from different fibres are separated in y-direction (with each spectrum covering several rows of the CCD array). Thus it is possible to measure the different spectra simultaneously. Unfortunately the instrumental transmission function for the individual viewing directions may not be sufficiently similar to allow ratioing to the zenith, thus two dimensional spectrometers are best combined with technique 3 (see above). 


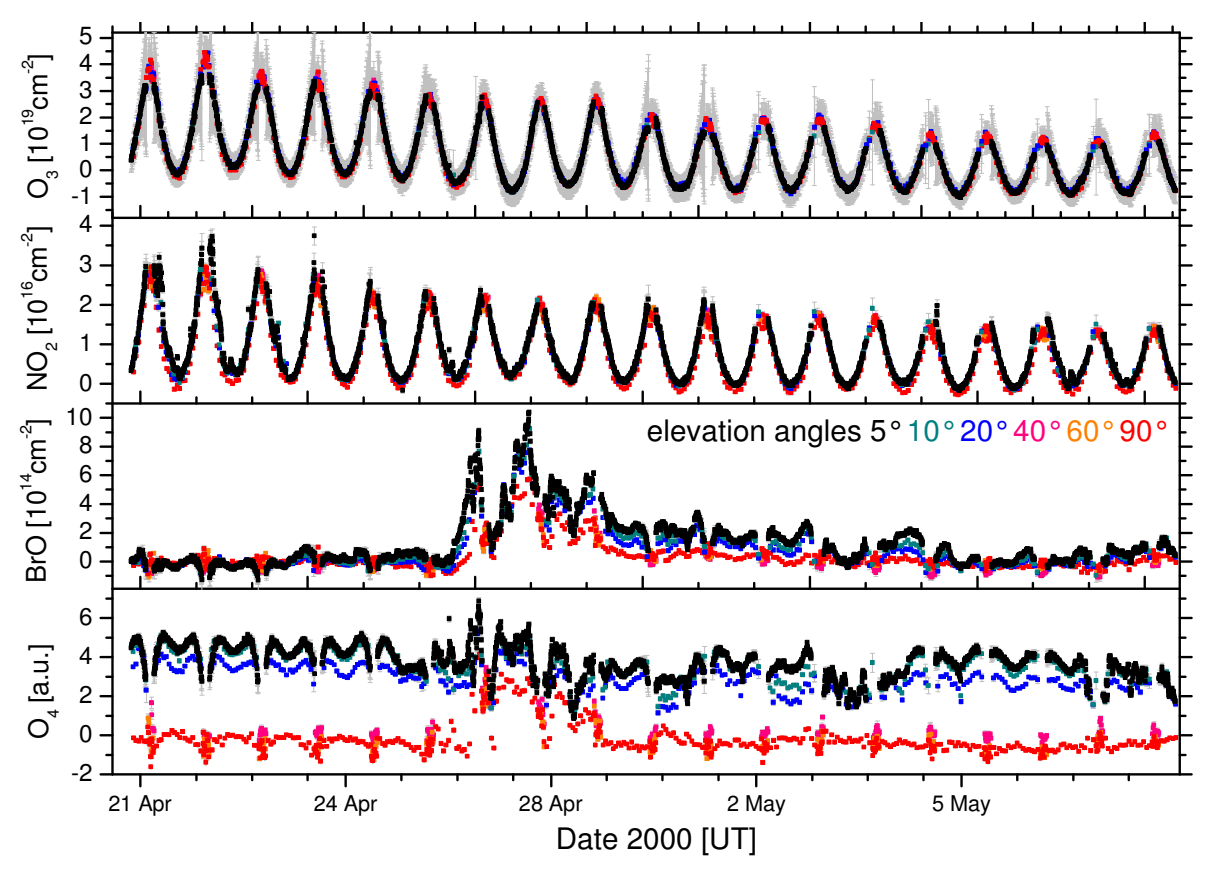

Fig. 18. MAX-DOAS time series of DSCD's of $\mathrm{O}_{3}, \mathrm{NO}_{2}, \mathrm{O}_{4}$ and $\mathrm{BrO}$ at Alert during spring of 2000. Error bars $(2 \sigma)$ are shown in light grey. The $\mathrm{O}_{3}$ and $\mathrm{NO}_{2}$ columns show no variation for the different elevation angles indicating that the bulk of these species is located in the stratosphere. In contrast to that the $\mathrm{O}_{4}$ data vary strongly with elevation angle. Enhanced $\mathrm{O}_{4}$ levels around 27/28 April at high elevation angles indicate periods of snowdrift. Following 27 April the BrO columns show strong differences for different elevation angles due to BrO presence in the boundary layer. Effects of snowdrift on 27/28 April can be seen like for $\mathrm{O}_{4}$.

\section{MAX-DOAS observations}

\subsection{Comparison of measured and modelled SCD's}

As discussed above, RTM calculations yield airmass factors for a priori trace gas profiles with the elevation angle as important parameter. This permits the derivation of vertical profile information from actual MAX-DOAS measurements. DSCD's, which result from the MAX-DOAS analysis for different elevation angles, are usually differential SCD's with respect to a Fraunhofer reference spectrum taken at the zenith viewing direction. In order to eliminate possible bias $\triangle \mathrm{SCD}$ 's are either directly derived by choosing a spectrum taken simultaneously or within short time as Fraunhofer reference for the DOAS analysis. This procedure yields $\triangle$ SCD's, which can also be calculated from DSCD's (when only a single FRS was taken for the entire DOAS analysis) as shown in Sect. 2 above.

Here $\alpha=90^{\circ}$ was assumed for recording the FRS, however, in special cases a different viewing direction could be chosen for the FRS.

Figure 17 shows an example for measurements taken during the Polar Sunrise Experiment Alert 2000 by Hönninger and Platt (2002). Measured data points ( $\triangle$ SCD's) are plotted as a function of the elevation angle. Additionally the model predicted $\triangle \mathrm{SCD}$ 's calculated from the boundary layer column $\mathrm{BL}-\mathrm{VCD}=2 \times 10^{13} \mathrm{~cm}^{-2}$ and the differential AMF $\triangle \mathrm{AMF}(\alpha)=\mathrm{A}(\alpha)-\mathrm{A}\left(\alpha=90^{\circ}\right)$ are shown for the model layers P1-P6. The measured values agree well with the model results for $\mathrm{P} 1$, representing a constant trace gas profile over the lowest $1 \mathrm{~km}$ of the atmosphere. The other profiles are not compatible with the measured data in this case. It can also be seen that the most significant differences between the modelled $\triangle \mathrm{SCD}$ 's for the various profiles appear at the low elevation angles. For deriving vertical profile information using MAX-DOAS, measurements at low elevation angles are therefore crucial.

First MAX-DOAS observations of $\mathrm{BrO}$ in the Arctic boundary layer (Alert, $82.5^{\circ} \mathrm{N}$ ) during spring of 2000 were already reported by Hönninger and Platt (2002). Here we show a more comprehensive data set including stratospheric absorbers and $\mathrm{O}_{4}$. Figure 18 shows the MAX-DOAS results (time series of 3 weeks), where the change in solar zenith angle is very small compared to mid-latitudes (diurnal $\left.\triangle \mathrm{SZA}=15^{\circ}\right) . \quad \mathrm{O}_{3}$ and $\mathrm{NO}_{2}$ show the typical pattern of stratospheric absorbers, which only depend on the SZA. Changes in tropospheric $\mathrm{O}_{3}$ are masked by the large stratospheric $\mathrm{O}_{3}$ column. The vertical ozone column changes only by about $1 \%$ in the high Arctic during polar sunrise, where the whole boundary layer ozone column is destroyed during frequent episodes of boundary layer ozone depletion. With the AMF for the stratospheric ozone column in the range of 5 at $\mathrm{SZA}=80^{\circ}$, even the high sensitivity of MAX-DOAS at the surface is not sufficient to measure this effect of typically 


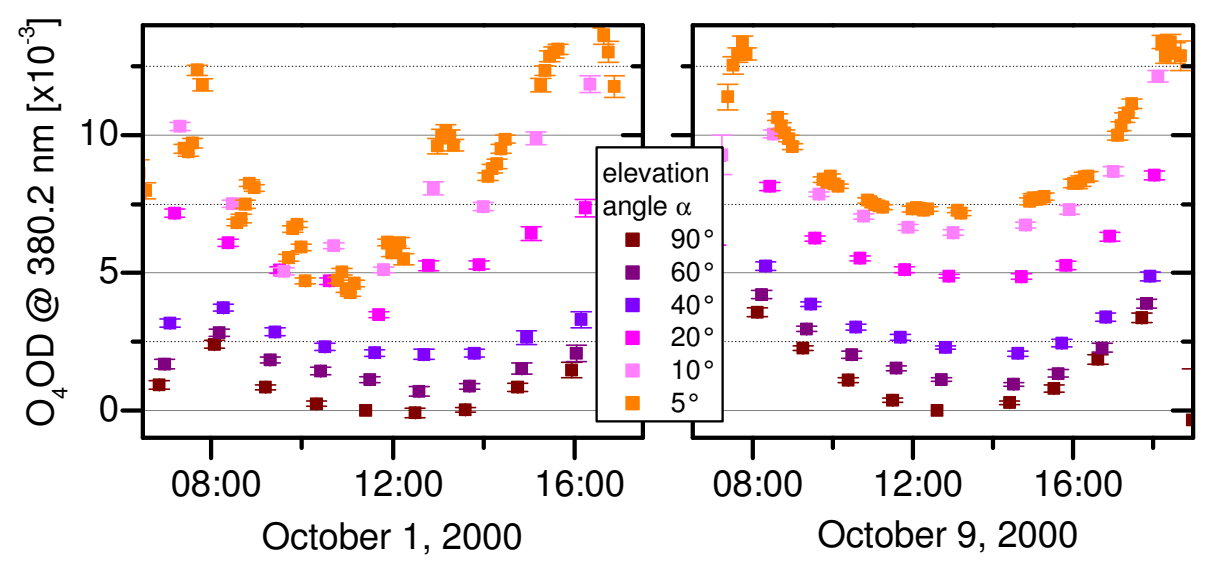

Fig. 19. $\mathrm{O}_{4}$ absorption at different elevation angles in mid-latitudes. Clearly visible is the pattern of increasing $\mathrm{O}_{4}$ absorption with decreasing elevation angle. The regular pattern shown for a cloud-free day on the right is disturbed only for the lowest elevation angles on a cloudy day (left). The Multi Axis effect is much stronger than the overlaid U-shape pattern which is due to the change in SZA (Leser, 2001; Leser et al., 2003).

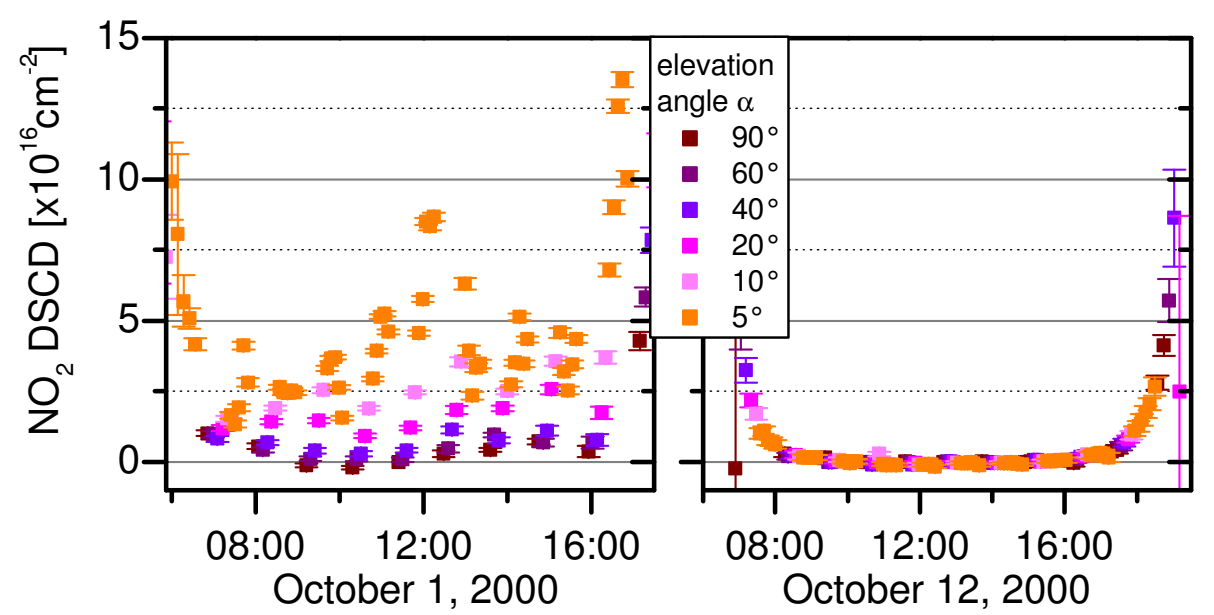

Fig. 20. Shown are two examples of $\mathrm{NO}_{2}$ DSCD's, one for a case with pollution observed in the lower troposphere (left panel, North Sea, 1 October 2000), the right panel shows stratospheric background $\mathrm{NO}_{2}$ only with no significant differences between the individual elevation angles (Leser, 2001; Leser et al., 2003).

2-3\%. In the $\mathrm{NO}_{2}$ time series several pollution events (21, 22, 26 April, 7 May) can be identified as low elevation angle data points deviating from the general pattern which tracks the SZA change. These episodes are always correlated to exhaust plumes being blown into the MAX-DOAS viewing direction which originated either from a nearby generator or from the Alert base at several kilometres distance. On 27 April $2000 \mathrm{BrO} \Delta \mathrm{SCD}$ 's rise from background levels of $<10^{13} \mathrm{molec} / \mathrm{cm}^{2}$ up to $10^{15} \mathrm{molec} / \mathrm{cm}^{2}$ and simultaneously large differences can be seen between the used MAX-DOAS elevation angles. Hönninger and Platt (2002) inferred a BrO layer of roughly $1 \mathrm{~km}$ thickness at the surface from the MAXDOAS results at 4 different elevation angles using only single scattering RTM calculations. Episodes of drifting snow (e.g. on 27/28 April) can also be modelled with the new RTM by von Friedeburg (2003). Also a more comprehensive investi- gation of the evolvement of the $\mathrm{BrO}$ layer over time is possible (von Friedeburg, 2003). $\mathrm{O}_{4}$ shows very little diurnal variation but the typical change in absorption with changing elevation angle for a lower tropospheric absorber. Effects of multiple scattering can be seen for the drifting snow period between 26 and 29 April (Hönninger, 2002). The measured column densities are elevated for all viewing directions as a result of enhanced light path lengths in the lowest atmospheric layer. Additional information on the aerosol profile can be derived by applying the approach mentioned above (see Sect. 4, sensitivity studies $\mathrm{O}_{4}$ ).

Another example illustrating the effects of clouds on the radiative transfer and the detection by MAX-DOAS is shown in Fig. 19 for measurements at mid-latitudes. Ship borne MAX-DOAS measurements of $\mathrm{BrO}, \mathrm{NO}_{2}$ and $\mathrm{O}_{4}$ were performed during a cruise of the German research vessel 


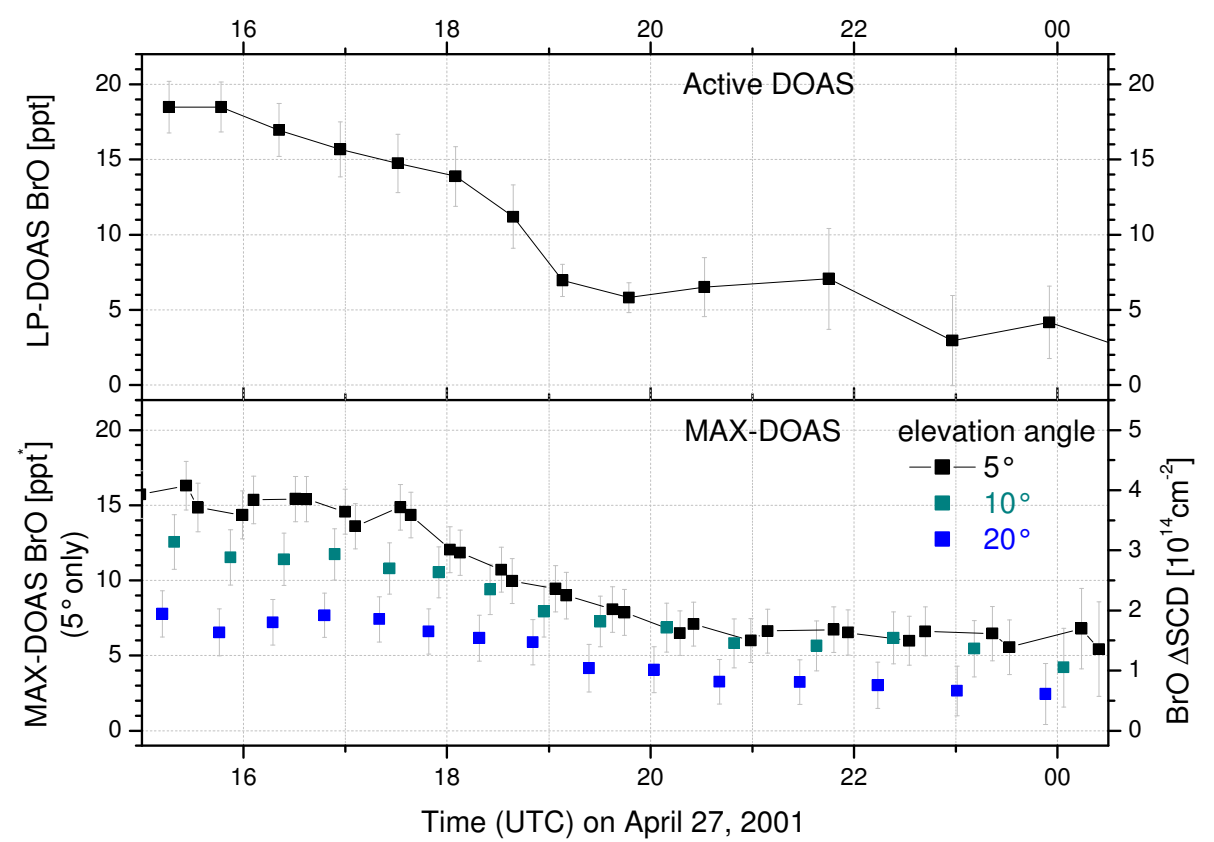

Fig. 21. Comparison of active long path DOAS and passive MAX-DOAS BrO measurements at the Hudson Bay for 27 April 2001. From the elevation angle dependence of the $\triangle$ SCD's a $\sim 1 \mathrm{~km}$ BrO layer at the surface can be concluded for e.g. 16:00 h. Using this layer thickness the $5^{\circ} \mathrm{BrO} \triangle \mathrm{SCD}$ 's were converted to mixing ratios for better comparison with the long path DOAS data (Hönninger et al., 2003a).

FS Polarstern from Bremerhaven, Germany to Cape Town, South Africa (Leser, 2001; Leser et al., 2003). A major difference in comparison with the above example at high latitudes is the range of the solar zenith angle over the course of the day. In Fig. 19 the strong influence of the change in SZA on the MAX-DOAS measurements can be seen as U-shaped diurnal pattern. Leser et al. (2003) presented a method to account for the change in SZA during sequential MAX-DOAS measurements by fitting a polynomial function to the diurnal DSCD pattern and calculating $\triangle$ SCD's using interpolated values for $\mathrm{SCD}_{\mathrm{FRS}}$. This method was applied successfully for measurements at mid-latitudes by Leser et al. (2003). On the partly cloudy day shown in Fig. 19 (left) enhanced DSCD's due to light path enhancement in clouds are seen for the lowest elevation angles $\left(5^{\circ}, 10^{\circ}\right.$ and $\left.20^{\circ}\right)$.

Another application of ground-based MAX-DOAS is the study of tropospheric pollutants like $\mathrm{NO}_{2}$ and $\mathrm{SO}_{2}$. During the ship borne MAX-DOAS measurements by (Leser, 2001; Leser et al., 2003) it was also possible to study pollution episodes. Figure 20 demonstrates the sensitivity of MAXDOAS to $\mathrm{NO}_{2}$ in the boundary layer in the North Sea. During enhanced $\mathrm{NO}_{2}$ levels in the boundary layer the typical pattern of strongly increasing DSCD with decreasing elevation angle is found on 1 October 2000 (Fig. 20, left panel) when the ship cruised in the North Sea. On 12 October 2000 a typical U-shaped diurnal pattern of DSCD's with no significant differences between the measurements at various elevation angles shown in Fig. 20 (right panel) represents stratospheric background $\mathrm{NO}_{2}$ and an unpolluted troposphere.

\section{Comparison of passive MAX-DOAS with active long path-DOAS}

During a field campaign at the south-east shore of the Hudson Bay, Canada, simultaneous measurements of $\mathrm{BrO}$ using an active Long path-DOAS system (e.g. Platt 1994) and a passive MAX-DOAS instrument were performed. The active long path DOAS yielded average $\mathrm{BrO}$ concentrations over a $7.6 \mathrm{~km}$ light path at $\sim 30 \mathrm{~m}$ altitude above the sea ice surface. The passive MAX-DOAS was also set-up on a hill $\sim 30 \mathrm{~m}$ above the sea ice. It used elevation angles of $5^{\circ}, 10^{\circ}, 20^{\circ}$ and $90^{\circ}$ above the horizon and the viewing azimuth was true north, less than $10^{\circ}$ relative to the long path DOAS light path, so the same airmass was sampled in both cases (Hönninger et al., 2004a).

An example of the intercomparison results is shown in Fig. 21. From noon to sunset the $\mathrm{BrO}$ as measured by the long path DOAS system showed high $\mathrm{BrO}$ values of $18 \mathrm{ppt}$ $\mathrm{BrO}$ at noon decreasing to $<5 \mathrm{ppt}$ in the evening. The MAXDOAS BrO $\triangle$ SCD's are shown in the lower part of Fig. 21 for the elevation angles of $5^{\circ}, 10^{\circ}$ and $20^{\circ}$. Around 16:00 $\mathrm{h}$ the elevation angle dependence compares best with a $\sim 1 \mathrm{~km}$ $\mathrm{BrO}$ layer at the surface. Therefore, the $5^{\circ} \Delta \mathrm{SCD}$ 's were converted to mixing ratios using this assumption. Indeed, the absolute values of the MAX-DOAS mixing ratios (black data points and line in Fig. 21, bottom panel) match the Long path-DOAS data (top panel of Fig. 21) very well. Small differences can be explained by variability of the boundary layer thickness. It can also be seen that the time resolution 
of the MAX-DOAS instrument (5 min for one single measurement, $30 \mathrm{~min}$ for a complete MAX-DOAS scan, with somewhat longer times during morning/evening twilight periods) is comparable to and often better than that of the active DOAS (30 min-1 h)(Hönninger et al., 2004a).

\section{Other MAX-DOAS applications}

Besides the basic MAX-DOAS geometries described above many additional variants are possible, which have specific advantages for the measurement in particular situations. In the following we give a few examples:

\subsection{MAX-DOAS from elevated standpoints}

One possible application of the MAX-DOAS approach is to make observations from elevated standpoints, e.g. towers, mountains, balloons, or aircraft, which allows studies of:

- Emission patterns of source areas near the instrument,

- vertical profiles of trace gases on local and regional scales,

- free tropospheric background conditions and pollution episodes in Alpine environments,

- smog episodes in valleys which are isolated from the free troposphere by temperature inversions.

A possible MAX-DOAS experiment to study halogen release processes associated with the surface of a salt flat is shown in Fig. 22. High albedo surfaces of salt (also snow, sea surface glint, etc.) increase the light intensity and thereby the sensitivity of the measurements. In the sketched case background absorption can be easily determined and corrected for in order to yield slant column densities in the layer between the MAX-DOAS altitude and the salt lake surface. The spherically averaged absorption signal for the atmosphere above the MAX-DOAS site can be determined by analysing scattered and direct sunlight collected by a $2 \pi$ integrating optics (e.g. known from measurements of down welling actinic fluxes by filter- and spectroradiometers, Junkermann et al., 1989). The light collected by this device is representative for the light which is then diffusely reflected by the high albedo salt surface. Measuring only the direct sunlight would not be appropriate since in the blue and UV spectral ranges a significant fraction of the down welling solar radiation is scattered sunlight, even under clear sky conditions $(\sim 80 \%$ at $300 \mathrm{~nm}$, $\sim 40 \%$ at $420 \mathrm{~nm}$, Lefer et al., 2001). Thus one MAX-DOAS telescope should measure this signal, which can then be used to correct slant column densities derived from the various geometries observing different locations of the bright surface below the instrument. Spatially resolved trace gas concentrations can be derived, depending on the scale of inhomogeneities, by applying analytical or numerical inversion tech-

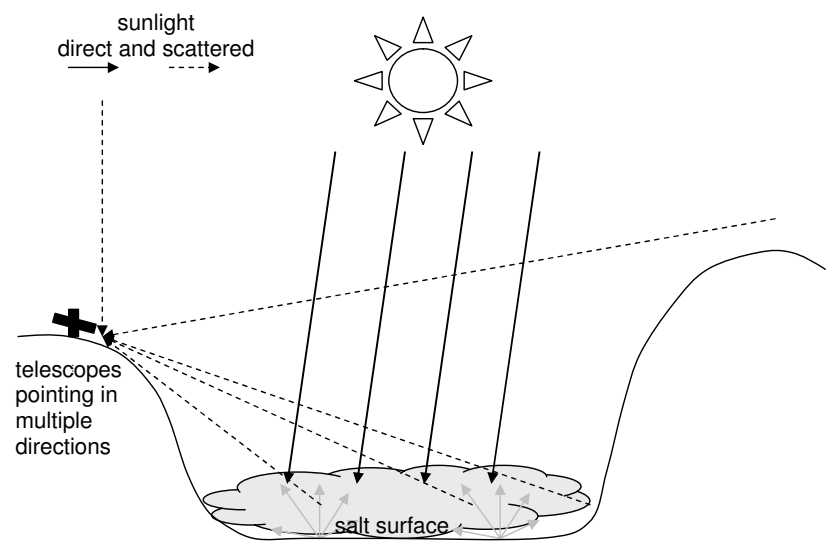

Fig. 22. Salt flat MAX-DOAS set-up: Horizontal and vertical emission patterns of halogen compounds can be measured.

niques. This information can improve the knowledge of reactive halogen release processes, known to occur on sea ice or salt surfaces (Hebestreit et al., 1999; Platt, 2000; Stutz et al., 2002; Hönninger et al., 2004b). Possible local inhomogeneities including vertical profiles can be studied by MAXDOAS observations using multiple viewing directions, for example observing light at different azimuth and elevation angles. In addition artificial high reflectivity surfaces may be used. For instance, a quite well-defined absorption path would result from the measurement, from several kilometres away, of reflected light, from a patch of high reflectivity (e.g. a SPECTRALON sheet) of size a square meter or so. A quasi-long path absorption measurement is possible with this set-up.

The background signal, containing absorption from the higher tropospheric layers and the stratosphere, can be eliminated by correction with zenith sky absorption measurements. Vertical profiles can be measured by pointing the light receiving telescopes at bright surfaces (e.g. snow or ice) at different altitudes. Pollution in valleys can be monitored from mountains by observing light scattered back from the usually cloudy top of the inversion layers which frequently isolate the air in the valleys. Multiple scattering in the valley leads to large absorption paths and absorption signals in the observed backscattered light. Besides being useful for simple, qualitative assessment of trace gas distributions, this method can also be used to calculate concentrations by ratioing to the simultaneously measured $\mathrm{O}_{4}$ absorption, which is proportional to the effective light path.

A quite flexible deployment strategy is to mount the spectrometer on an aircraft (e.g. Wagner et al., 2002; Wang et al., 2003; Heue et al., 2003) known as Airborne MAX-DOAS (AMAX-DOAS). Other possible platforms include remotely piloted aircraft, airships ("Zeppelin" type dirigibles) and balloons.

Note that the assumption of a straight well-defined light path between the observed high albedo surface and the 


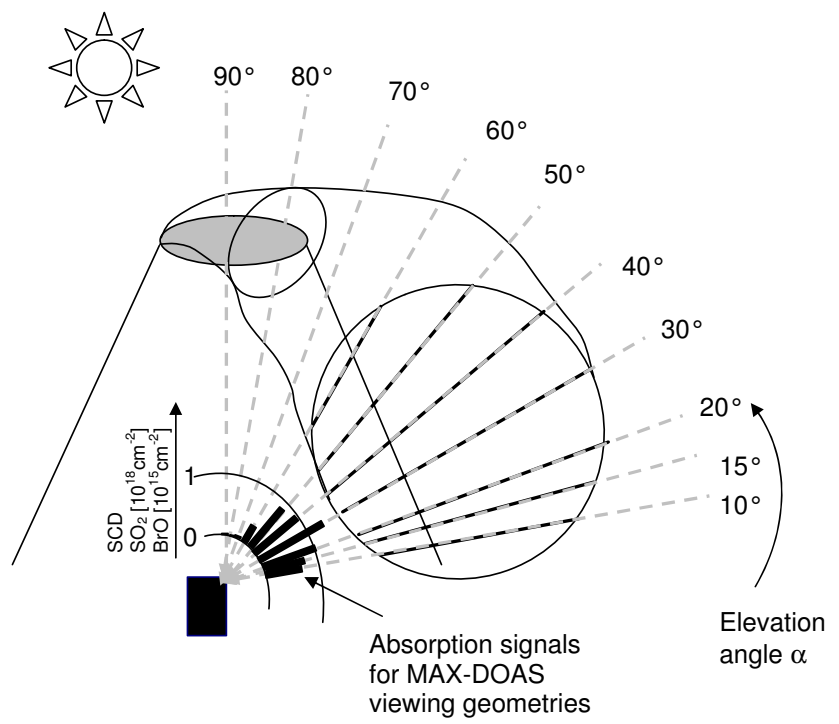

Fig. 23. Emission plume monitoring by MAX-DOAS: A volcano as emission source is shown as an example. MAX-DOAS measurements yield spatial information as well as concentration and emission flux data for several trace gases. As an example the viewing directions used by (Bobrowski, 2002; Bobrowski et al., 2003) are sketched and the distribution of the SCD signals of the first scan of Fig. 24 for $\mathrm{BrO}$ is included.

MAX-DOAS instrument is valid for many cases due to the relatively long mean free path of photons at higher altitudes ( $>21 \mathrm{~km}$ for $360 \mathrm{~nm}$ at $3000 \mathrm{~m}$ altitude).

8.2 Industrial, urban, biomass burning and volcanic plume monitoring

Routine monitoring of trace gases involved in urban air pollution is also a possible application for the MAX-DOAS technique. While the method does not yield localized concentration data like point measurements from in situ monitors, it is very sensitive to major pollutants (e.g. $\mathrm{NO}_{2}, \mathrm{SO}_{2}$, $\mathrm{HCHO}$, etc.) and average concentrations in the boundary layer can be derived. For instance MAX-DOAS measurements of $\mathrm{NO}_{2}$ near a highway were described by von Friedeburg (2003). In fact, average concentrations often prove to be much more useful than highly variable, in situ measurements which have to be averaged over time. This is particularly true when characterizing the levels of pollution in cities and urban areas. Sensitivity studies using airmass factor modelling and actual measurements performed by Hönninger and Platt (2002) show that MAX-DOAS measurements alone provide sufficient information to derive the approximate height of the mixing layer and calculate average mixing ratios. Certainly in highly polluted environments where variable visibility is a major problem for other optical monitoring techniques (e.g. long path DOAS) MAX-DOAS measurements are better suited because the method also works at low visi-

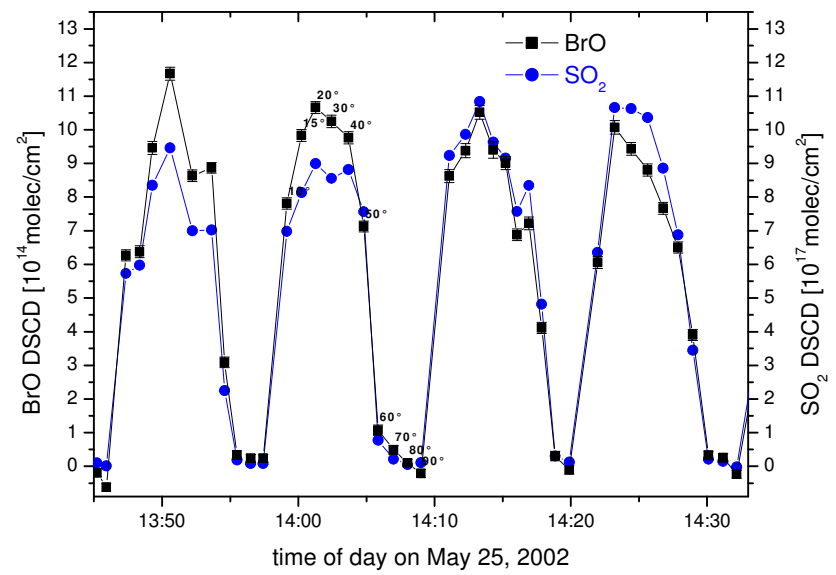

Fig. 24. Example of a series of MAX-DOAS scans across a volcanic plume. Volcanic gases like $\mathrm{SO}_{2}$ and $\mathrm{BrO}$ show high DSCD's when the viewing direction crosses the plume, background values are found outside the plume (Bobrowski, 2002; Bobrowski et al., 2003). For the second scan the $\mathrm{BrO}$ data points are labelled with the respective MAX-DOAS elevation angle.

bility. In case of inhomogeneous trace gas distributions frequently found near emission sources in urban regions retrieving profile information from MAX-DOAS measurements is further complicated. However, average trace gas levels derived from MAX-DOAS measurements are less likely to be affected by non-homogeneous distributions than localized measurements using in situ instruments. A further advance on scattered sunlight DOAS, the so-called "Imaging DOAS" (Lohberger et al. 2004), which can be applied to study for example non-homogeneous plumes by taking two dimensional images of trace gas distributions. With the airmass factor concepts and in particular using information from simultaneous $\mathrm{O}_{4}$ absorption measurements as described in this paper, quantitative measurements during cloudy and low visibility periods are also possible. Apart from scattered sunlight, the high albedos of certain points in urban areas or even guided mirrors to observe reflected sunlight provide another potential source of MAX-DOAS observation geometries.

An instrumental set-up of MAX-DOAS for the study of volcanic (Galle et al., 2003; Bobrowski et al., 2003) or other emission plumes is sketched in Fig. 23. MAX-DOAS can be applied by sequentially scanning spectra from different geometries or simultaneous measurements using an imaging spectrometer with 2D-CCD detector coupled to several telescopes. The combination of different elevation angles and two instruments at different locations allows a derivation of the exact plume distance as well. Examples of typical MAX-DOAS scans across a volcanic plume are shown in Fig. 24 (Bobrowski et al., 2003). Trace gas column densities increase strongly when the MAX-DOAS viewing direction crosses the plume, while background column densities are measured outside the plume. Compared with localized 
measurements at the crater rim or airborne measurements within the plume, MAX-DOAS is not sensitive to inhomogeneities of the plume but rather averages across the absorption path. Temporal variability of emission patterns can be studied by automated MAX-DOAS measurements over a longer time period.

The advantage of MAX-DOAS over traditional passive techniques (i.e. COSPEC, Millan et al., 1969; Davies, 1970) is the much higher time resolution and the reduced effect of fluctuations inside the plume on the measurement results. Additionally many trace gases (such as $\mathrm{SO}_{2}, \mathrm{NO}_{2}, \mathrm{CH}_{2} \mathrm{O}$, $\mathrm{BrO}, \mathrm{CS}_{2}$ rather than just $\mathrm{SO}_{2}$ or - after refitting the instrument with another mask $-\mathrm{NO}_{2}$ ) can be measured simultaneously with MAX-DOAS. Recent instrument developments allow the use of rugged, lightweight MAX-DOAS instruments with relatively low power consumption (Galle et al., 2003; Bobrowski et al., 2003). Compared to active DOAS measurements MAX-DOAS requires much simpler instrumentation, yields profile information, however gives less definite concentration data, and is only useable during daylight hours.

\section{Conclusions}

In this study we have shown that Multi Axis DOAS is an emerging, new variant of the scattered light DOAS method. It is based on mature instrumental techniques which have been established over the last decades albeit for other purposes. Although its development is still ongoing, MAXDOAS has proven to be successful in several applications including monitoring volcanic plumes $\left(\mathrm{SO}_{2}, \mathrm{BrO}\right)$, natural emission of trace gases (e.g. reactive bromine, $\mathrm{BrO}$ ) from salt lakes, sea ice, and the ocean surface as well as for pollution monitoring. Further applications like study of urban or forest fire plumes, studies of three dimensional trace gas distributions (von Friedeburg, 2003), balloon borne applications, or study of radiative transfer in clouds still remain to be fully explored.

Although MAX-DOAS cannot replace active DOAS or other complimentary measurement techniques (e.g. for nighttime observations an active system is needed), in many cases MAX-DOAS is a powerful alternative to traditional methods. As shown in this paper, there are numerous applications where successful measurements have been performed using MAX-DOAS and, in fact, a series of measurements has become only possible because of MAX-DOAS. Particular advantages of MAX-DOAS are the simple and compact instrumentation, the easy deployment and low power consumption (passive technique), the fact that vertical profile information of gases up to several kilometres above the ground can be derived in combination with RTM calculations and the high time resolution also during low visibility conditions. Using advanced radiative transfer models, the slant column densities derived for the various MAX-DOAS viewing di- rections can be interpreted and combined to yield a more complete data product than other measurement platforms can provide. Additionally, information on aerosol profiles and properties can be obtained from MAX-DOAS $\mathrm{O}_{4}$ (and $\mathrm{O}_{2}$ ) measurements which are a by-product of most MAX-DOAS applications. With these aerosol data, necessary input for the RTM can be taken from the very measurement without need for further instrumentation. In the future, enhanced data analysis algorithms for MAX-DOAS combining spectral analysis, radiative transfer modelling and inversion techniques for profile retrieval will further extend the capabilities of MAXDOAS.

Acknowledgements. Part of the work presented here was supported by the European Union under Contract No. EVK2-CT-1999-00033 and by the German Ministery of Education and Research (BMBF) under grant No. 07ATF38. G. Hönninger thanks the German Academic Exchange Service for financial support.

\section{References}

Aliwell, S. R., Jones, R. L., and Fish, D. J.: Mid-latitude observations of the seasonal variation of $\mathrm{BrO}, 1$. Zenith-sky measurements, Geophys. Res. Lett. 24, 1195-1198, 1997.

Arpaq, K. H., Johnston, P. V., Miller, H. L., Sanders, R. W., and Solomon, S.: Observations of the stratospheric BrO column over Colorado, 40 N, J. of Geophys. Res., 99, D4, 8175-8181, 1994.

Axelson, H., Galle, B., Gustavson, K., Ragnarsson, P., and Rudin, M.: A Transmitting/Receiving Telescope for DOASMeasurements using Retroreflektor Technique., Techn. Dig. Ser., 4, 641-644, 1990.

Bobrowski, N., Hönninger, G., Galle, B., and Platt, U.: Detection of Bromine Monoxide in a Volcanic Plume, Nature 423, 273-276, doi:10.1038/nature01625, 2003.

Bossmeyer, J.: Ship-Based Multi-Axis Differential Optical Absorption Spectroscopy Measurements of Tropospheric Trace Gases over the Atlantic Ocean - New Measurement Concepts, Diploma thesis, Institut für Umweltphysik, University of Heidelberg, Germany, 2002.

Burrows, J., Platt, U., Chance, K., Vountas, M., Rozanov, V., Richter, A., Haug, H., and Marquard, L.: Study of the Ring Effect, Noordvijk, The Netherlands: European Space Agency, 1996.

Bussemer, M.: Der Ring-Effekt: Ursachen und Einfluß auf die spektroskopische Messung stratosphärischer Spurenstoffe, Diploma Thesis, Institut für Umweltphysik, Universität Heidelberg, 1993.

Davies, J.: Correlation Spectroscopy, Analytical Chemistry, 42, 101-112, 1970.

Dobson, G. M. B. and Harrison, D. N.: Measurements of the amount of ozone in the Earth's Atmosphere and its Relation to other Geophysical Conditions, Proc. R. Soc. London, 110, 660693, 1926.

Eisinger, M., Richter, A., Ladstätter-Weißenmayer, A., and Burrows, J. P.: DOAS Zenith sky observations: 1 . BrO measurements over Bremen $\left(53^{\circ} \mathrm{N}\right)$ 1993-1994, J. Atmos. Chem. 26 93-108, 1997. 
Erle, F., Pfeilsticker, K., and Platt, U.: On the influence of tropospheric clouds on zenith-scattered light measurements of stratospheric species, Geophys. Res. Lett., 22, 2725-2728, 1995.

Fiedler, M. H., Frank, T., Gomer, M., Hausmann, K., Pfeilsticker, K., and Platt, U.: Groundbased spectroscopic measurements of stratospheric $\mathrm{NO}_{2}$ and OClO in the arctic winter 1989/1990, Geophys. Res. Lett., 20, 10, 963-966, 1993.

Fish, D. J. and Jones, R. L.: Rotational Raman scattering and the Ring effect in zenith-sky spectra, Geophys. Res. Lett., 22, 811814, 1995.

Friess, U., Wagner, T., Pundt, I., Pfeilsticker, K., and Platt, U.: Spectroscopic Measurements of Tropospheric Iodine Oxide at Neumayer Station, Antarctica, Geophys. Res. Lett., 28, 19411944, 2001

Friess, U., Hollwedel, J., König-Langlo, G., Wagner, T., and Platt, U.: Dynamics and chemistry of tropospheric bromine explosion events in the Antarctic, J. Geophys. Res., in press, 2004.

Galle, B., Oppenheimer, C., Geyer, A., McGonigle, A., Edmonds, M., and Horrocks, L.: A miniaturised ultraviolet spectrometer for remote sensing of $\mathrm{SO}_{2}$ Fluxes: A new tool for volcano surveillance, J. Volcanol. Geotherm. Res., 119, 214-254, 2003.

Götz, P. F. W., Meetham, A. R., and Dobson, G. M. B.: The Vertical Distribution of Ozone in the Atmosphere, Proc. Roy. Soc., A 145, 416-446, 1934.

Grainger, J. and Ring, J.: Anomalous Fraunhofer line profiles, Nature, 193, 762, 1962.

Greenblatt, G. D., Orlando, J. J., Burkholder, J. B., and Ravishankara, A. R.: Absorption Measurements of Oxygen Between 330 and 1140 nm, J. Geophys. Res., 95, 18 577-18 582, 1990.

Harder, J. W., Jakoubek, R. O., and Mount, G. H.: Measurement of tropospheric trace gases by long-path differential absorption spectroscopy during the $1993 \mathrm{OH}$ Photochemistry Experiment, J. Geophys. Res., 102, 6215-6226, 1997.

Harrison, A. W.: Midsummer stratospheric $\mathrm{NO}_{2}$ at latitude $40^{\circ} \mathrm{S}$, Can. J. Phys., 57, 1110-1116, 1979.

Heckel, A.: Messungen troposphärischer Spurengase mit einem MAX-DOAS-Instrument Nachweis von troposphärischem Formaldehyd in Norditalien während der Format Kampagne, Diploma Thesis, University of Bremen, 2003.

Heismann, B.: Eine CCD-Kamera zur Messung atmosphärischer Spurenstoffe, Diploma Thesis, University of Heidelberg, 1996.

Heue, K.-P., Bruns, M., Burrows, J., Lee, W.-D., Platt, U., Pundt, I., Richter, A., Schulz, B., Wagner, T., and Wang, P.: Airborne Multi Axis DOAS Measurements During the SCIAVALUES and FORMAT Campaigns, Geophysical Research Abstracts, 5, 12405 , 2003.

Hoff, R. and Millan, M.: Remote $\mathrm{SO}_{2}$ mass flux measurements using COSPEC. JAPCA, 31, 381-384, 1981.

Hoff, R. M.: Differential $\mathrm{SO}_{2}$ Column Measurements of the Mt. Pinatubo Volcanic Plume, Geophys. Res. Lett., 19, 175-178, 1992.

Hönninger, G.: Halogen Oxide Studies in the Boundary Layer by Multi Axis Differential Optical Absorption Spectroscopy and Active Longpath-DOAS, Ph.D. thesis, Universität Heidelberg, Institut für Umweltphysik, http://www.ub.uni-heidelberg. de/archiv/1940, 2002.

Hönninger, G. and Platt, U.: Observations of $\mathrm{BrO}$ and its vertical distribution during surface ozone depletion at Alert, Atmos. Environ., 36, 2481-2489, 2002.
Hönninger, G., Leser, H., Sebastián, O., and Platt, U.: Groundbased Measurements of Halogen Oxides at the Hudson Bay by Active Longpath DOAS and Passive MAX-DOAS, Geophys. Res. Lett., accepted, doi:10.1029/2003GL018982, 2004a.

Hönninger, G., Bobrowski, N., Palenque, E. R., Torrez, R., and Platt, U.: Bromine and sulfur emissions from Salar de Uyuni, Bolivia, Geophys. Res. Lett., accepted, doi:10.1029/2003GL018818, 2004b.

Junkermann, W., Platt, U., and Volz-Thomas, A.: A photoelectric detector for the measurement of photolysis frequencies of ozone and other atmospheric molecules, J. Atmos. Chem., 8, 203-227, 1989.

Kaiser, N.: Off-axis-Messungen von troposphärischem $\mathrm{NO}_{3}$, Diplomarbeit, Universität Heidelberg, 1997.

Kattawar, G. W., Young, A. T., and Humphreys, T. J.: Inelastic scattering in planetary atmospheres. I. The Ring Effect, without aerosols, Astrophys. J., 243, 1049-1057, 1981.

Kreher, K., Johnston, P. V., Wood, S. W., and Platt, U.: Groundbased measurements of tropospheric and stratospheric $\mathrm{BrO}$ at $\mathrm{Ar}-$ rival Heights ( $\left.78^{\circ} \mathrm{S}\right)$, Antarctica. Geophys. Res. Lett., 24, 30213024, 1997.

Lefer, B., Hall, S., Cinquini, L., and Shetter, R.: Photolysis frequency measurements at the South Pole during ISCAT-98, Geophys. Res. Lett., 28, 19, 3637-3640, 2001.

Leser, H.: Untersuchung troposphärischer Spurenstoffe mit Multiaxialer Differentieller Optischer Absorptionsspektroskopie von gestreutem Sonnenlicht (MAX-DOAS). Diploma Thesis, Institut für Umweltphysik, Universität Heidelberg, 2001.

Leser, H., Hönninger, G., and Platt, U.: MAX-DOAS Measurements of $\mathrm{BrO}$ and $\mathrm{NO}_{2}$ in the Marine Boundary Layer, Geophys. Res. Lett., doi:10.1029/2002GL015811, 2003.

Lohberger, F., Hönninger, G., and Platt, U.: Ground based Imaging Differential Optical Absorption Spectroscopy of atmospheric gases, Appl. Opt., revised, 2004.

Löwe, A. G., Adukpo, D., Fietkau, S., Heckel, A., LadstätterWeißenmayer, A., Medeke, T., Oetjen, H., Richter, A., Wittrock, F., and Burrows, J. P.: Multi-Axis-DOAS observations of atmospheric trace gases at different latitudes by the global instrument network BREDOM, Proc. 10th Sci. Conf. of IAMAS, CACGP and 7th Sci. Conf. of IGAC, Sept., Crete, 2002.

Marquard, L., Wagner, T., and Platt, U.: Improved Air Mass Factor Concepts for Scattered Radiation Differential Optical Absorption Spectroscopy of Atmospheric Species, J. Geophys. Res., 105, 1315-1327, 2000.

McElroy, C., McLinden, C., and McConnell, J.: Evidence for bromine monoxide in the free troposphere during the Arctic polar sunrise, Nature, 397, 338-341, 1999.

McKenzie, R. L. and Johnston, P. V.: Seasonal variations in stratospheric $\mathrm{NO}_{2}$ at $45^{\circ} \mathrm{S}$, Geophys. Res. Lett. 9, 1255-1258, 1982.

McKenzie, R. L., Johnston, P. V., McElroy, C. T., Kerr, J. B., and Solomon, S.: Altitude distributions of stratospheric constituents from ground-based measurements at twilight, J. Geophys. Res. 96, 15 499-15 512, 1991.

Millan, M., Townsend, S., and Davies, J.: Study of the Barringer refractor plate correlation spectrometer as a remote sensing instrument, Utias rpt. 146, m.a.sc. thesis, University of Toronto, Toronto, Ontario, Canada, 1969.

Mount, G.: The measurement of tropospheric $\mathrm{OH}$ by long path absorption, 1, Instrumentation, J. Geophys. Res., 97, 2427-2444, 
1992.

Miller, H. L., Weaver, A., Sanders, R. W., Arpag, K., and Solomon, S.: Measurements of arctic sunrise surface ozone depletion events at Kangerlussuaq, Greenland $\left(67^{\circ} \mathrm{N}, 51^{\circ} \mathrm{W}\right)$, Tellus, $49 \mathrm{~B}$, 496-509, 1997.

Noxon, J. F.: Nitrogen Dioxide in the Stratosphere and Troposphere measured by Ground-based Absorption Spectroscopy. Science, 189, 547-549, 1975.

Noxon, J. F., Whipple, E. C., and Hyde, R. S.: Stratospheric $\mathrm{NO}_{2}, 1$. Observational Method and Behavior at Midlatitudes, J. Geophys. Res., Vol. 84, 5047-5076, 1979.

Oetjen, H.: Messung atmosphärischer Spurengase in Ny Aalesund, Aufbau und Inbetriebnahme eine neuen DOAS-Meßsystems, Diploma Thesis, University of Bremen, 2002.

Perliski, L. M. and Solomon, S.: On the evaluation of air mass factors for atmospheric near ultraviolet and visible absorption spectroscopy, J. Geophys. Res., 98, 10 363-10374, 1993.

Perner, D., Ehhalt, D. H., Pätz, H. W., Platt, U., Röth, E. P., and Volz, A.: OH Radicals in the lower Troposphere, Geophys. Res. Lett., 3, 466-468, 1976.

Perner, D. and Platt, U.: Detection of Nitrous Acid in the Atmosphere by Differential Optical Absorption, Geophys. Res. Lett., 6, 917-920, 1979.

Petritoli, A., Ravegnani, F., Giovanelli, G., Bortoli, D., Bonafe, U., Kostadinov, I., Oulanovsky, A.: Off-Axis Measurements of Atmospheric Trace Gases by Use of an Airborne Ultraviolet-Visible Spectrometer, Applied Optics-LP, 41, 27, 5593-5599, 2002.

Pfeilsticker, K., Erle, F., Funk, O., Marquard, L., Wagner, T., and Platt, U.: Optical path modifications due to tropospheric clouds: Implications for zenith sky measurements of stratospheric species, J. Geophys. Res., 103, D19, 25 323-25 335, 1998.

Plane, J. M. C., and Smith, N.: Atmospheric monitoring by differential optical absorption spectroscopy, in Spectroscopy in Environmental Sciences, edited by Hester, R. E. and Clark, R. J. H., John Wiley, New York, 223-262, 1995.

Platt, U., Marquard, L., Wagner, T., and Perner, D.: Corrections for Zenith Scattered Light DOAS, Geophys. Res. Letters, 24, 14, 1759-1762, 1997.

Platt, U. and Perner, D.: Direct Measurements of Atmospheric $\mathrm{CH}_{2} \mathrm{O}, \mathrm{HNO}_{2}, \mathrm{O}_{3}, \mathrm{NO}_{2}$ and $\mathrm{SO}_{2}$ by Differential Optical Absorption in the Near UV, J. Geophys. Res., 85, 7453-7458, 1980.

Platt, U., Perner, D., Harris, G. W., Winer, A. M., and Pitts Jr., J. M.: Detection of $\mathrm{NO}_{3}$ in the Polluted Troposphere by Differential Optical Absorption, Geophys. Res. Lett., 7, 89-92, 1980.

Platt, U., Perner, D., and Pätz, H. W.: Simultaneous Measurement of Atmospheric $\mathrm{CH}_{2} \mathrm{O}, \mathrm{O}_{3}$ and $\mathrm{NO}_{2}$ by Differential Optical Absorption, J. Geophys. Res., 84, 6329-6335, 1979.

Platt, U.: Differential optical absorption spectroscopy (DOAS), in Air Monitoring by Spectroscopic Techniques, edited by: Sigrist, M. W., Chemical Analysis Series, 127, John Wiley, New York, 1994.

Platt, U.: Reactive Halogen Species in the Troposphere - Recent Discoveries, Water, Air, and Soil Pollution, 123, 229-244, 2000.

Pommereau, J. P. and Piquard, J.: Observations of the vertical distribution of stratospheric OClO, Geophys. Res. Lett., 21, 12311234, 1994.

Richter, A., Eisinger, M., Ladstätter Weißenmayer, A., Wittrock, F., Burrows, J. P.: DOAS zenith-sky observations: 2. Seasonal variations of $\mathrm{BrO}$ over Bremen $\left(53^{\circ} \mathrm{N}\right)$ 1994-1995, J. Atmos. Chem. 32, 83-99, 1999.

Rodgers, C. D.: Retrieval of atmospheric temperature and composition from remote measurements of thermal radiation, Rev. Geophys. 14, No. 4, 609-624, 1976.

Sanders, R. W., Solomon, S., Smith, J. P., Perliski, L., Miller, H. L., Mount, G. H., Keys, J. G., and Schmeltekopf, A. L.: Visible and Near-Ultraviolet Spectroscopy at McMurdo Station Antarctica, 9. Observations of OClO from April to October 1991, J. Geophys. Res., 98, D4, 7219-7228, 1993.

Sioris, C. E. and Evans, W. F. J.: Filling in of Fraunhofer and gasabsorption lines in sky spectra as caused by rotational Raman scattering, Appl. Opt., 38, 12, 2706-2713, 1999.

Smith, J. and Solomon, S.: Atmospheric $\mathrm{NO}_{3}$ : 3. Sunrise Disappearance and the Stratospheric Profile, J. Geophys. Res., 95, D9, 13 819-13 827, 1990.

Smith, J., Solomon, S., Sanders, R., Miller, H., Perliski, J., Keys, J., and Schmeltekopf, A.: Atmospheric $\mathrm{NO}_{3}$ : 4. Vertical Profiles at Middle and Polar Latitudes at Sunrise, J. Geophys. Res., 98, D5, 8983-8989, 1993.

Solomon, S., Mount, H. G., Sanders, R. W., and Schmeltekopf, A. L.: Visible spectroscopy at McMurdo station, Antarctica 2. Observations of OClO, J. Geophys. Res., 92, 8329-8338, 1987a.

Solomon, S., Schmeltekopf, A. L., and Sanders, R. W.: On the interpretation of zenith sky absorption measurements, J. Geophys. Res., 92, 8311-8319, 1987b.

Solomon, S., Mount, G. H., Sanders, R. W., Jakoubek, R. O., and Schmeltekopf, A. L.: Observations of the nighttime abundance of $\mathrm{OClO}$ in the winter stratosphere above Thule, Greenland, Science 242, 550-555, 1988.

Solomon, S., Sanders. R. W., Carroll, M. A., and Schmeltekopf, A. L.: Visible and near-ultraviolet spectroscopy at McMurdo station, Antarctica, 5, Diurnal variations of OClO and BrO, J. Geophys. Res., 94, 11393-11 403, 1989.

Solomon, S., Smith, J. P., Sanders, R. W., Perliski, L., Miller, H. L., Mount, G. H., Keys, J. G., and Schmeltekopf, A. L.: Visible and near-ultraviolet spectroscopy at McMurdo station, Antarctica, 8, Observations of nighttime $\mathrm{NO}_{2}$ and $\mathrm{NO}_{3}$ from April to October 1991, J. Geophys. Res., 98, 993-1000, 1993.

Stoiber, R. and Jepsen, A.: Sulfur dioxide contribution to the atmosphere by volcanoes, Science, 182, 577-578, 1973.

Stutz, J. and Platt, U.: Numerical Analysis and Estimation of the Statistical Error of Differential Optical Absorption Spectroscopy Measurements with Least-Squares methods, Appl. Opt., 35, 30, 6041-6053, 1996.

Stutz, J. and Platt, U.: Improving long-path differential optical absorption spectroscopy with a quartz-fiber mode mixer, Applied Optics, 36, 6, 1105-1115, 1997.

von Friedeburg, C., Wagner, T., Geyer, A., Kaiser, N., Vogel, B., Vogel, H., and Platt, U.: Derivation of Tropospheric $\mathrm{NO}_{3}$ Profiles Using Off-axis-DOAS Measurements During Sunrise and Comparison with Simulations, J. Geophys. Res., 107, D13, doi:10.1029/2001JD000481, 2002.

von Friedeburg, C.: Derivation of Trace Gas Information combining Differential Optical Absorption Spectroscopy with Radiative Transfer Modelling, Ph.D. Thesis, IUP Heidelberg, Heidelberg, http://www.ub.uni-heidelberg.de/archiv/3758, 2003.

Wagner, T., Erle, F., Marquard, L., Otten, C., Pfeilsticker, K., Senne, T., Stutz, J., and Platt, U.: Cloudy sky optical paths as derived 
from differential optical absorption spectroscopy observations, J. Geophys. Res., 103, D19, 25 307-25 321, 1998.

Wagner, T., von Friedeburg, C., Wenig, M., and Platt, U.: UVvisible observations of atmospheric $\mathrm{O}_{4}$ absorptions using direct moonlight and zenith-scattered sunlight, For clearsky and cloudy sky conditions, J. Geophys. Res., 107, D20, 4424, 2002.

Wagner, T., Bruns, M., Burrows, J. P., Fietkau, S., Finocchi, F., Heue, K.-P., Hönninger, G., Platt, U., Pundt, I., Richter, A., Rollenbeck, R., von Friedeburg, C., Wittrock, F., and Xie, P.: The AMAX-DOAS Instrument and its Application for SCIAMACHY Validation, Report, 2002.

Wahner, A., Jakoubek, R. O., Mount, G. H., Ravishankara, A. R. and Schmeltekopf, A. L.: Remote sensing observations of daytime column $\mathrm{NO}_{2}$ during the airborne antarctic ozone experiment, August 22 to October 2, 1987, J. Geophys. Res., 94, 16619-16632, 1989.
Wang, P., Bruns, M., Richter, A., Burrows, J. P., Heue, K.-P., Pundt, I., Wagner, T., Platt, U.: Validation of SCIAMACHY with AMAX-DOAS Measurements from the DLR Falcon, Geophysical Research Abstracts, 5, 09341, 2003.

Weaver, A., Solomon, S., Sanders, R. W., Arpag, K., and Miller, H. L.: Atmospheric $\mathrm{NO}_{3}$ 5. Off-axis measurements at sunrise: Estimates of tropospheric $\mathrm{NO}_{3}$ at $40^{\circ} \mathrm{N}, \mathrm{J}$. Geophys. Res., 101, D13, 18 605-18612, 1996.

Wittrock, F., Müller, R., Richter, A., Bovensmann, H., and Burrows, J. P.: Measurements of iodine monoxide (IO) above Spitsbergen, Geophys. Res. Lett., 27, 1471-1474, 2000.

Wittrock, F., Oetjen, H., Richter, A., Fietkau, S., Medeke, T., Rozanov, A., and Burrows, J. P.: MAX-DOAS Measurements of atmospheric trace gases in Ny-Ålesund, Atm. Chem. Phys. Discuss. 3, 6109-6145, 2003. 